\title{
Thermomechanical fatigue crack growth in a single crystal nickel base superalloy
}

Frans Palmert, J ohan Moverare and David Gustafsson

The self-archived postprint version of this journal article is available at Linköping University Institutional Repository (DiVA):

http:/ / urn.kb.se/ resolve?urn=urn:nbn:se:liu:diva-154074

N.B.: When citing this work, cite the original publication.

Palmert, F., Moverare, J ., Gustafsson, D., (2019), Thermomechanical fatigue crack growth in a single crystal nickel base superalloy, International J ournal of Fatigue.

https:// doi.org/ 10.1016/j.ijfatigue.2019.01.014

Original publication available at:

https:/ / doi.org/ 10.1016/j.ijfatigue.2019.01.014

Copyright: Elsevier

http:// www.elsevier.com/

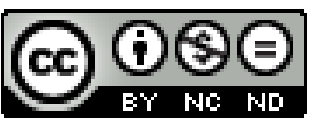




\title{
Thermomechanical fatigue crack growth in a single crystal nickel base superalloy
}

\author{
Authors: Frans Palmert ${ }^{\mathrm{a}, \mathrm{b}}$, Johan Moverare ${ }^{\mathrm{a}}$, David Gustafsson ${ }^{\mathrm{b}}$ \\ a: Division of Engineering Materials, Dept. of Management and Engineering, Linköping University, 58183 \\ Linköping, Sweden.
}

b: Siemens Industrial Turbomachinery AB, Materials Technology, SE-61283 Finspång, Sweden.

Corresponding author: Frans Palmert, phone: +46725426005, frans.palmert@siemens.com

\begin{abstract}
Thermomechanical fatigue crack growth in a single crystal nickel base superalloy was studied. Tests were performed on single edge notched specimens, using in phase and out of phase thermomechanical fatigue cycling with temperature ranges of $100-750^{\circ} \mathrm{C}$ and $100-850^{\circ} \mathrm{C}$ and hold times at maximum temperature ranging from 10 s to 6h. Isothermal testing at $100^{\circ} \mathrm{C}, 750^{\circ} \mathrm{C}$ and $850^{\circ} \mathrm{C}$ was also performed using the same test setup. A compliancebased method is proposed to experimentally evaluate the crack opening stress and thereby estimate the effective stress intensity factor range $\Delta K_{\text {eff }}$ for both isothermal and nonisothermal conditions. For in phase thermomechanical fatigue, the crack growth rate is increased if a hold time is applied at the maximum temperature. By using the compliance-based crack opening evaluation, this increase in crack growth rate was explained by an increase in the effective stress intensity factor range which accelerated the cycle dependent crack growth. No significant difference in crack growth rate vs $\Delta K_{\text {eff }}$ was observed between in phase thermomechanical fatigue tests and isothermal tests at the maximum temperature. For out of phase thermomechanical fatigue, the crack growth rate was insensitive to the maximum temperature and also to the length of hold time at maximum temperature. The crack growth rate vs $\Delta K_{\text {eff }}$ during out of phase thermomechanical fatigue was significantly higher than during isothermal fatigue at the minimum temperature, even though the advancement of the crack presumably occurs at the same temperature. Dissolution of $\gamma^{\prime}$ precipitates and recrystallization at the crack tip during out of phase thermomechanical fatigue is suggested as a likely explanation for this difference in crack growth rate.
\end{abstract}

Keywords: single crystal superalloy, thermomechanical fatigue, crack growth, crack closure 


\section{Introduction}

Single crystal nickel base superalloys are frequently used for gas turbine blades due to their excellent ability to withstand high mechanical loads in combination with high temperatures. Each start/stop cycle of the gas turbine represents a cycle of thermomechanical fatigue (TMF) loading on the gas turbine blades. The increased usage of wind and solar power has increased the demand for complementary power production, balancing these intermittent energy sources. Gas turbines supplying such complementary power will experience frequent starts and stops. Frequent cycling puts new demands on the methodology for fatigue life prediction of gas turbine blades. Such predictions need to be based on materials data generated by testing under relevant conditions. This generally implies a need for TMF testing, where temperature and mechanical loading are cycled independently in order to accurately capture the temperature dependent aspects of the material behaviour ${ }^{1,2,3,4}$. TMF of nickel base superalloys has been studied previously, but the majority of the work has been aimed at characterizing the cyclic deformation behaviour and crack initiation life $5,6,7,8,9,10,11,12,13,14,15,16,17,18$. Only limited work has been done to investigate the crack growth behaviour under TMF conditions ${ }^{19,20,21,22,23,24,25}$. There is currently no standard for TMF crack growth testing and studies such as the present one thus provide valuable information for the formulation of such a standard in the future. To the authors' knowledge, no work has yet been published on TMF crack growth in a single crystal alloy, which is the subject of the present work. This is a challenging task, both due to the complex nature of the testing and also due to the complex material behaviour. The mechanical properties of single crystal nickel base superalloys are anisotropic, both in terms of elastic and inelastic properties. At temperatures below $600^{\circ} \mathrm{C}$, inelastic deformation is typically localized to the $\{111\}$ planes $^{26}$. Under some conditions, crystallographic crack growth occurs along the $\{111\}$ planes, even if these are far from perpendicular to the loading direction. For the specific single crystal alloy which is the focus of the present work, the crystallographic crack growth behaviour has been previously characterized and discussed in relation to findings for similar alloys ${ }^{27}$. In this previous work, the crack growth behaviour was studied under isothermal fatigue conditions in order to allow the usage of traditional, relatively simple testing procedures. The main focus was then on the crack growth behaviour at lower temperatures, representative of a gas turbine blade root. Due to the relatively low temperature of the blade root during operation, isothermal fatigue was considered as a reasonable approximation for the actual component loading. The present work focuses on the crack growth behaviour during TMF with a higher maximum temperature, representative of the part of the blade exposed to the hot gas stream. Testing under TMF conditions is in this case believed to be necessary in order to obtain relevant crack growth data, which motivates the usage of a more complex testing method. For a relevant evaluation of the data it was also found necessary to develop a method to estimate the crack opening stress. The aims of the present work are to improve the understanding of the material behaviour of the studied alloy under TMF conditions and also to improve the evaluation methodology for TMF crack growth testing. Tests were performed on single edge notched specimens, using in phase (IP) and out of phase (OP) TMF cycling with temperature ranges of $100-750^{\circ} \mathrm{C}$ and $100-850^{\circ} \mathrm{C}$ and hold times at maximum temperature ranging from $10 \mathrm{~s}$ to 6h. Isothermal testing at $100^{\circ} \mathrm{C}, 750^{\circ} \mathrm{C}$ and $850^{\circ} \mathrm{C}$ was also performed using the same test setup. 


\subsection{Tested material}

The tested material is a single crystal nickel base superalloy, similar to the alloy described in a publication by Reed et $\mathrm{al}^{28}$. Its main alloying elements, in order of decreasing wt\%, are as follows: Ni-Cr-Ta-Co-Al-W-Mo-Si-Hf-C-Ce. The microstructure mainly consists of a $\gamma$-matrix precipitation strengthened by approximately 50 vol\% of $\gamma^{\prime}$ particles. The majority of the $\gamma^{\prime}$ is in the form of primary cuboidal particles, but smaller secondary $\gamma^{\prime}$ particles are also present within the $\gamma$-channels. In addition, the microstructure also contains carbides and casting pores.

\subsection{Test specimens}

Two different single edge notch (SEN) specimens were used for the testing, see Figure 1. The purpose of using two different specimen geometries was to investigate if the crack growth rate was sensitive to the specimen geometry. The nominal crystal orientation was $<001>$ in the axial direction and $<010>$ in the crack depth direction, except for test 2 and test 4 in which the secondary crystal orientation was rotated by 22,5 $5^{\circ}$ from the $<010>$ direction.

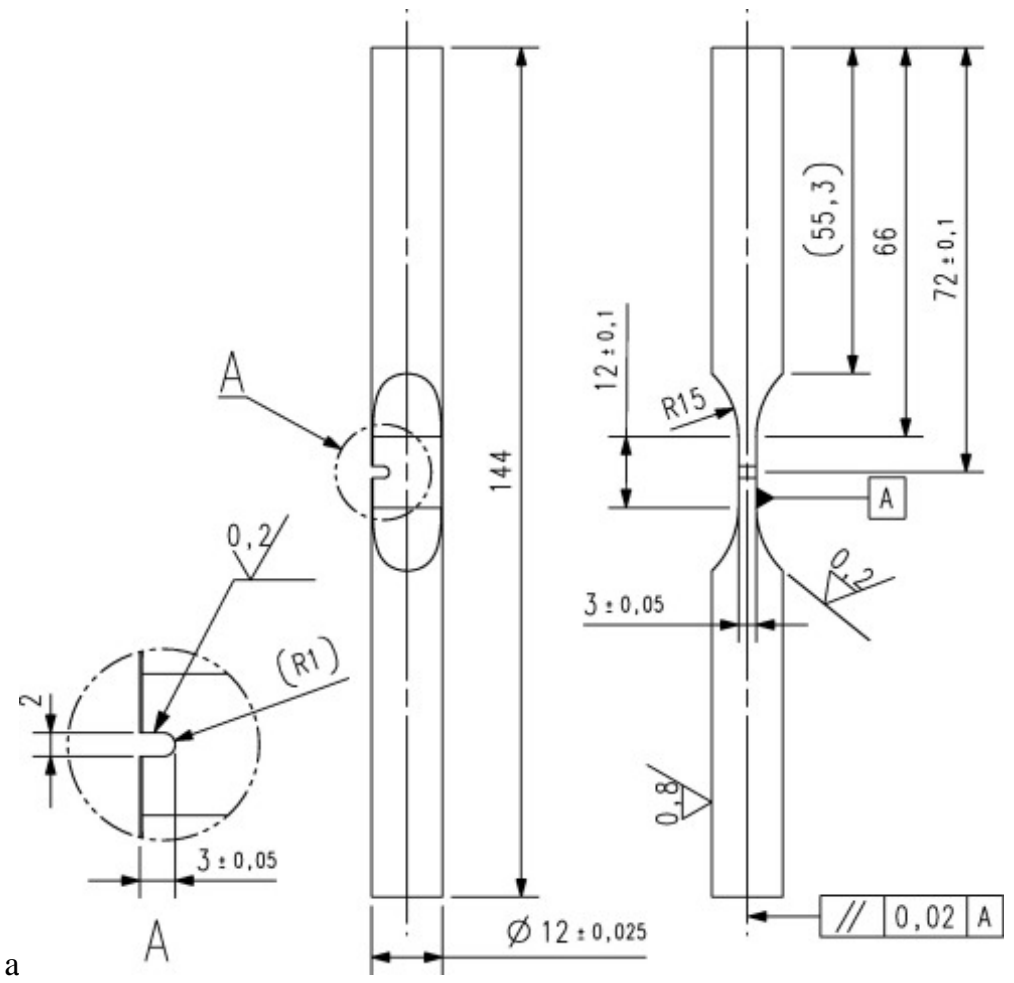




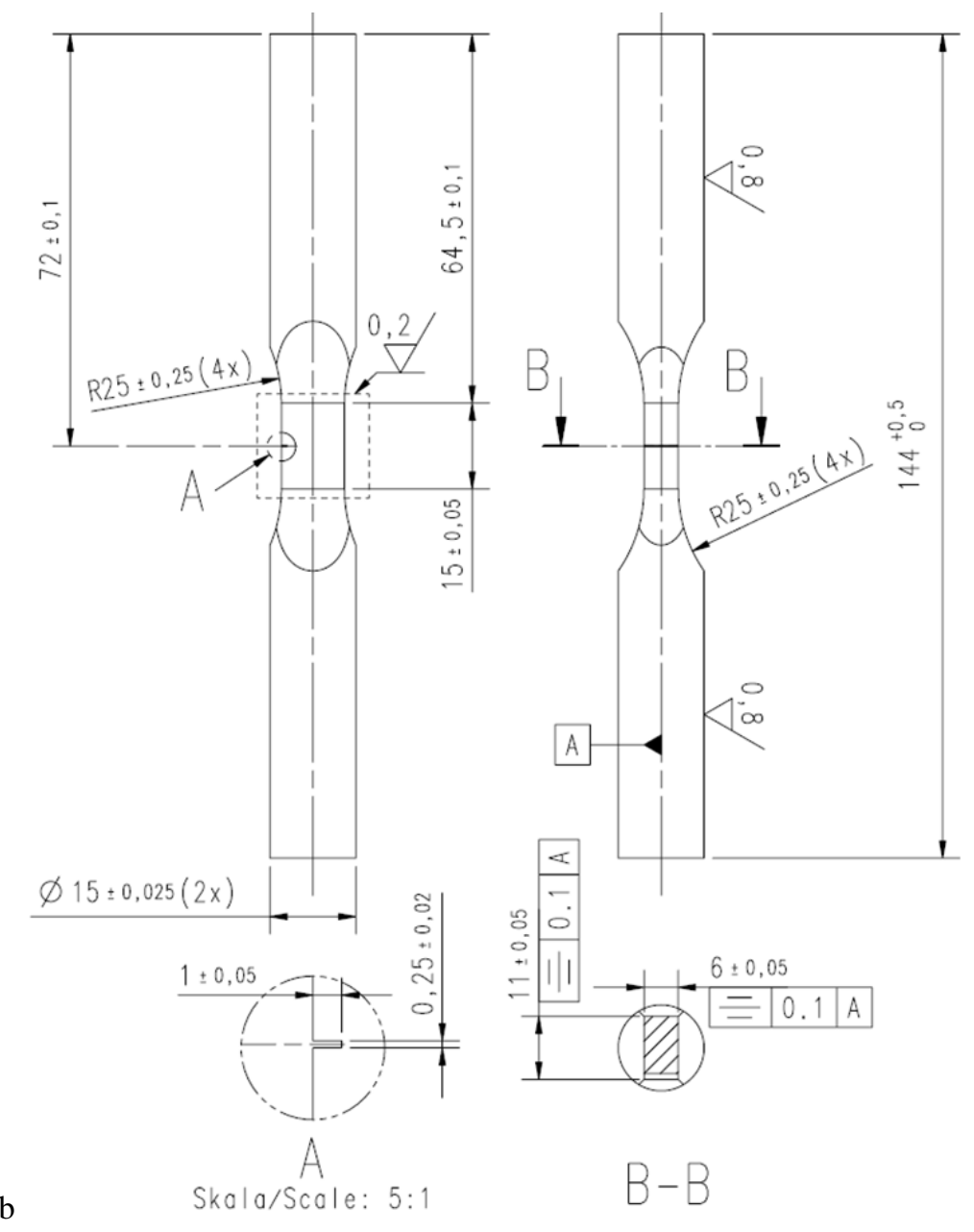

Figure 1 - Specimen drawings. a: Specimen SEN-1, b: Specimen SEN-2.

\subsection{Testing procedure}

The testing was performed on $100 \mathrm{kN}$ servo-hydraulic testing machines, using a test setup similar to the one previously used by Moverare ${ }^{22}$. The gauge length of the extensometer was $12 \mathrm{~mm}$. The specimen was heated by an induction coil and cooled by compressed air from two cooling nozzles, see Figure 2. The temperature was controlled using one thermocouple spot welded in the axial center of the gauge length on the side opposite the notch. A constant heating and cooling rate of $2^{\circ} \mathrm{C} / \mathrm{s}$ was used in all tests. A number of isothermal crack growth tests were also run using the same test setup. The crack length in each cycle was measured using the compliance method, adapted for TMF conditions, which is further described in 2.6. The stress intensity factor $K$ was calculated based on FE simulations for the two specimen geometries, under the assumption of isotropic elastic behaviour. In some of the tests with hold times of $1 \mathrm{~h}$ or $6 \mathrm{~h}$, significant creep deformation is observed. This suggests that small scale yielding conditions are not fulfilled and that the applicability of $K$ is questionable. It is however shown, in section 3.1 of the present work, that the crack growth rate has a strong correlation with $K$ and that the correlation is not significantly influenced by hold time or by the amount of inelastic deformation. Therefore, $K$ was considered as a suitable crack tip parameter for the analysis of the performed tests. 

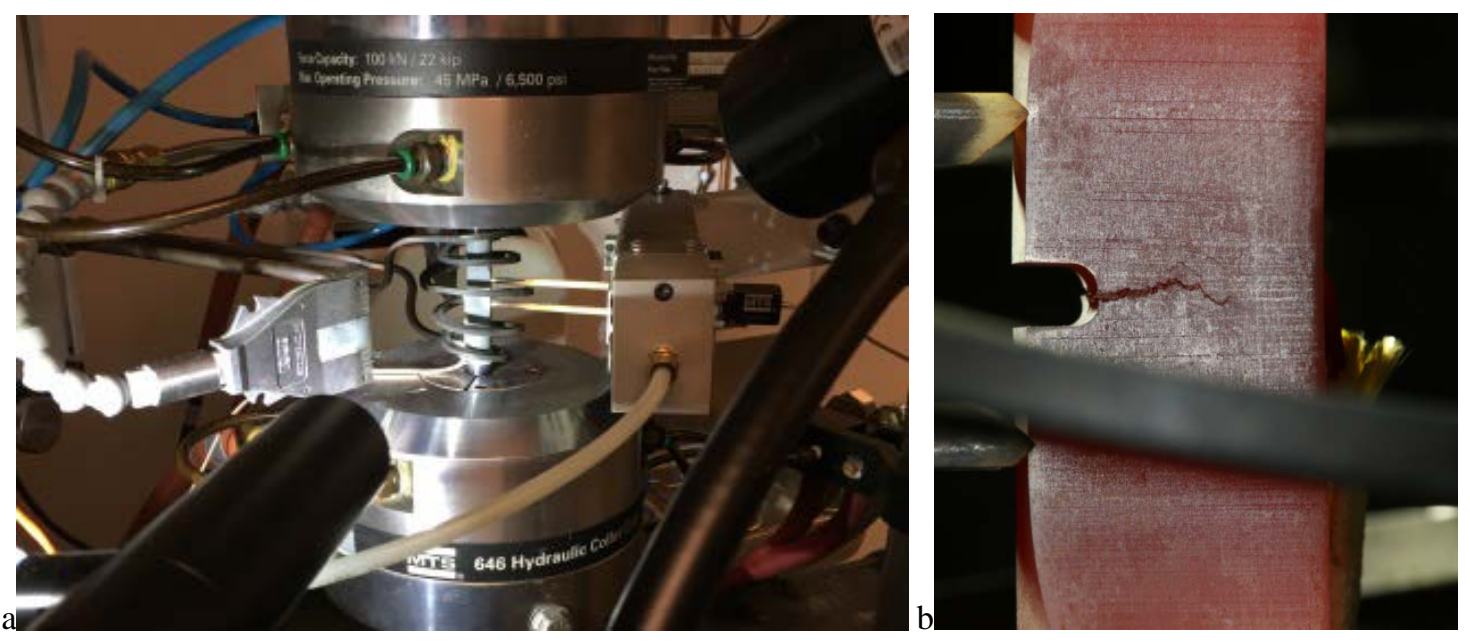

Figure 2 - a: Test set-up for TMF crack growth testing. b: Close-up of cracked specimen, showing the location of the extensometer rods. The controlling thermo couple is welded in the axial center of the gauge length on the side opposite the notch.

\subsection{Testing conditions}

All TMF tests were run in force control with either IP or OP thermal cycling, with maximum temperatures of $\mathrm{T}_{\max }=$ $750^{\circ} \mathrm{C}$ and $\mathrm{T}_{\max }=850^{\circ} \mathrm{C}$ and hold times of $10 \mathrm{~s}, 1 \mathrm{~h}$ or $6 \mathrm{~h}$. The testing conditions for all tests are summarized in Table 1. Isothermal cycling at elevated temperature $\left(750^{\circ} \mathrm{C}\right.$ or $\left.850^{\circ}\right)$ was used to create an initial Mode I crack of suitable length to start the TMF-CG test. Isothermal crack growth data is obtained from the pre-cracking. For the OP-TMF tests, the pre-cracking at elevated temperature was necessary in order to avoid the immediate crystallographic out-of-plane crack growth which occurred if the OP-TMF test was started without a pre-crack. The length of the pre-cracks was at least $0.8 \mathrm{~mm}$, measured from the notch root. The primary aim of the testing was to generate crack growth data for non-crystallographic cracks. In some cases, several different testing blocks with different dwell times were used for the same specimen, see Table 1. 
Table 1 - Test matrix

\begin{tabular}{|c|c|c|c|c|c|}
\hline Test number & $\begin{array}{l}\text { Specimen } \\
\text { Geometry }\end{array}$ & Type of test & $\mathbf{T}_{\max }\left[{ }^{\circ} \mathbf{C}\right]$ & Stress ratio, $\mathbf{R}$ & Dwell time [s] \\
\hline 1 & SEN-1 & IP-TMF & 750 & 0 & $\leq 10$ \\
\hline \multirow{2}{*}{2} & \multirow{2}{*}{ SEN-1 } & OP-TMF & 850 & -1 & $\leq 10$ \\
\hline & & OP-TMF & 850 & -1 & 3600 \\
\hline 3 & SEN-1 & OP-TMF & 850 & -1 & $\leq 10$ \\
\hline \multirow{2}{*}{4} & \multirow{2}{*}{ SEN-1 } & OP-TMF & 750 & -1 & $\leq 10$ \\
\hline & & OP-TMF & 750 & -1 & 3600 \\
\hline 5 & SEN-1 & Isothermal & 750 & -1 & $\leq 10$ \\
\hline \multirow{2}{*}{6} & \multirow{2}{*}{ SEN-1 } & IP-TMF & 750 & -1 & $\leq 10$ \\
\hline & & IP-TMF & 750 & -1 & 3600 \\
\hline \multirow{3}{*}{7} & \multirow{3}{*}{ SEN-1 } & Isothermal & 750 & -1 & $\leq 10$ \\
\hline & & IP-TMF & 750 & -1 & 3600 \\
\hline & & IP-TMF & 750 & -1 & 21600 \\
\hline \multirow{2}{*}{8} & \multirow{2}{*}{ SEN-1 } & IP-TMF & 750 & -1 & 3600 \\
\hline & & IP-TMF & 750 & -1 & 21600 \\
\hline \multirow{2}{*}{9} & \multirow{2}{*}{ SEN-1 } & Isothermal & 850 & -1 & $\leq 10$ \\
\hline & & IP-TMF & 850 & -1 & 3600 \\
\hline 10 & SEN-1 & Isothermal & 850 & -1 & $\leq 10$ \\
\hline \multirow{3}{*}{11} & \multirow{3}{*}{ SEN-1 } & Isothermal & 850 & -1 & $\leq 10$ \\
\hline & & IP-TMF & 850 & -1 & $\leq 10$ \\
\hline & & IP-TMF & 850 & -1 & 3600 \\
\hline \multirow{2}{*}{12} & \multirow{2}{*}{ SEN-1 } & Isothermal & 850 & -1 & $\leq 10$ \\
\hline & & Isothermal & 100 & -1 & $\leq 10$ \\
\hline \multirow{2}{*}{13} & \multirow{2}{*}{ SEN-1 } & Isothermal & 850 & -1 & $\leq 10$ \\
\hline & & Isothermal & 100 & 0 & $\leq 10$ \\
\hline 14 & SEN-1 & Isothermal & 850 & -1 & $\leq 10$ \\
\hline \multirow{3}{*}{15} & \multirow{3}{*}{ SEN-1 } & Isothermal & 850 & -1 & $\leq 10$ \\
\hline & & Isothermal & 850 & 0,5 & $\leq 10$ \\
\hline & & OP-TMF & 850 & 0 & $\leq 10$ \\
\hline \multirow{3}{*}{16} & \multirow{3}{*}{ SEN-2 } & Isothermal & 850 & -1 & $\leq 10$ \\
\hline & & IP-TMF & 850 & -1 & 3600 \\
\hline & & IP-TMF & 850 & -1 & 21600 \\
\hline \multirow{3}{*}{17} & \multirow{3}{*}{ SEN-2 } & Isothermal & 850 & -1 & $\leq 10$ \\
\hline & & IP-TMF & 850 & -1 & 3600 \\
\hline & & IP-TMF & 850 & -1 & 21600 \\
\hline \multirow{2}{*}{18} & \multirow{2}{*}{ SEN-2 } & Isothermal & 850 & -1 & $\leq 10$ \\
\hline & & IP-TMF & 850 & 0 & 3600 \\
\hline
\end{tabular}




\subsection{Post-test examination}

Some of the specimens were interrupted before final failure in order to allow microstructural investigation of the crack tip. Cross-sections were prepared at mid-thickness of the specimen by grinding and polishing down to $1 / 4 \mu \mathrm{m}$ grain size, followed by chemical polishing. No etching was performed on the specimens. The specimens were examined in a Hitachi SU70 FEG-SEM scanning electron microscope (SEM). In all micrographs, the loading axis is aligned in the vertical direction.

\subsection{Crack length measurement by the compliance method}

The crack length in each cycle was determined using the compliance method, adapted for TMF conditions. A detailed description of the method has been published by Ewest et al. ${ }^{29}$. The method utilizes the correlation between the crack length $a_{i}$ and the relative stiffness decrease $\beta_{i}$ of the specimen in cycle $i$. In practice the crack length varies through the thickness of the specimen and $a_{i}$ is defined as the average crack length. The function $\mathrm{f}_{\text {comp }}$ describes the relationship between $a_{i}$ and $\beta_{i}$, see Eq. (1). This function was obtained from finite element simulations verified by heat tint measurements in the same way as described in ${ }^{29}$.

$a_{i}=f_{\text {comp }}\left(\beta_{\mathrm{i}}\right)$

$\beta_{\mathrm{i}}=1-\frac{M_{\mathrm{i}, \text { unload }}\left(T_{\mathrm{a}}\right)}{M_{0, \text { unload }}\left(T_{\mathrm{a}}\right)}$

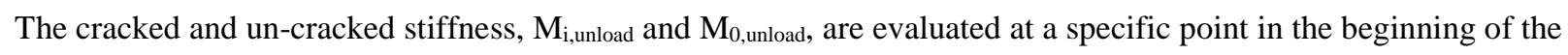
unloading ramp where the temperature is equal to $\mathrm{T}_{\mathrm{a}}$. This point is chosen so that the point itself and also surrounding points needed for stiffness evaluation correspond to elastic material behaviour and a fully open crack. Since the cracked and un-cracked stiffness is evaluated for the same temperature, the variation in elastic modulus with temperature has no influence on the evaluation.

\subsection{Crack driving force parameter}

In some of the tests with hold times of $1 \mathrm{~h}$ or 6h, significant creep deformation is observed. This suggests that small scale yielding conditions are not fulfilled and that the applicability of $K$ is questionable. It is however shown, in section 3.1 of the present work, that the crack growth rate displays a strong correlation with effective stress intensity factor range $\Delta K_{\text {eff, }}$ as defined in Eq. (1).

$\Delta K_{\mathrm{eff}}=K_{\max }-K_{\text {open }}$

In Eq. (1), $K_{\max }$ is the maximum stress intensity factor of the cycle and $K_{\text {open }}$ is the stress intensity factor at crack opening. This definition of the effective stress intensity factor range was first proposed by Elber ${ }^{30}$ with the motivation that there is no change in crack tip strain during cyclic loading of a closed crack and therefore only the 
portion of the cycle which is above $K_{\text {open }}$ contributes to the growth of the crack. Since the relation between da/dN and $\Delta K_{\text {eff }}$ is found to be unaffected by hold time or by the amount of inelastic deformation, $\Delta K_{\text {eff }}$ was considered as a suitable crack driving force parameter for the analysis of the performed tests. The stress intensity factor solution was calculated based on finite element simulations for the two specimen geometries SEN-1 and SEN-2, under the assumption of isotropic elastic behaviour.

\subsection{TMF crack growth evaluation code}

A Matlab code was developed to evaluate the data. The evaluation is done in four steps as described below.

\section{1) Characterization of thermal strain error}

a) Characterize the systematic error in thermal strain calculated by the testing software for the specific specimen, by evaluating thermal cycles at zero force. In the TMF testing software, the thermal strain as a function of temperature is described by a single polynomial function fitted to a thermal cycle at zero force. In practice, the thermal strain vs temperature during heating differs from the thermal strain vs temperature during cooling. The use of a single polynomial function, that represents both heating and cooling, results in a systematic error in thermal strain.

b) Fit two piecewise polynomial functions describing the error vs temperature during heating and cooling respectively.

c) Plot functions and raw data to ensure a reasonable fit and save the functions from " $1 \mathrm{~b}$ ” as two piecewise polynomial structures, see Figure 3.

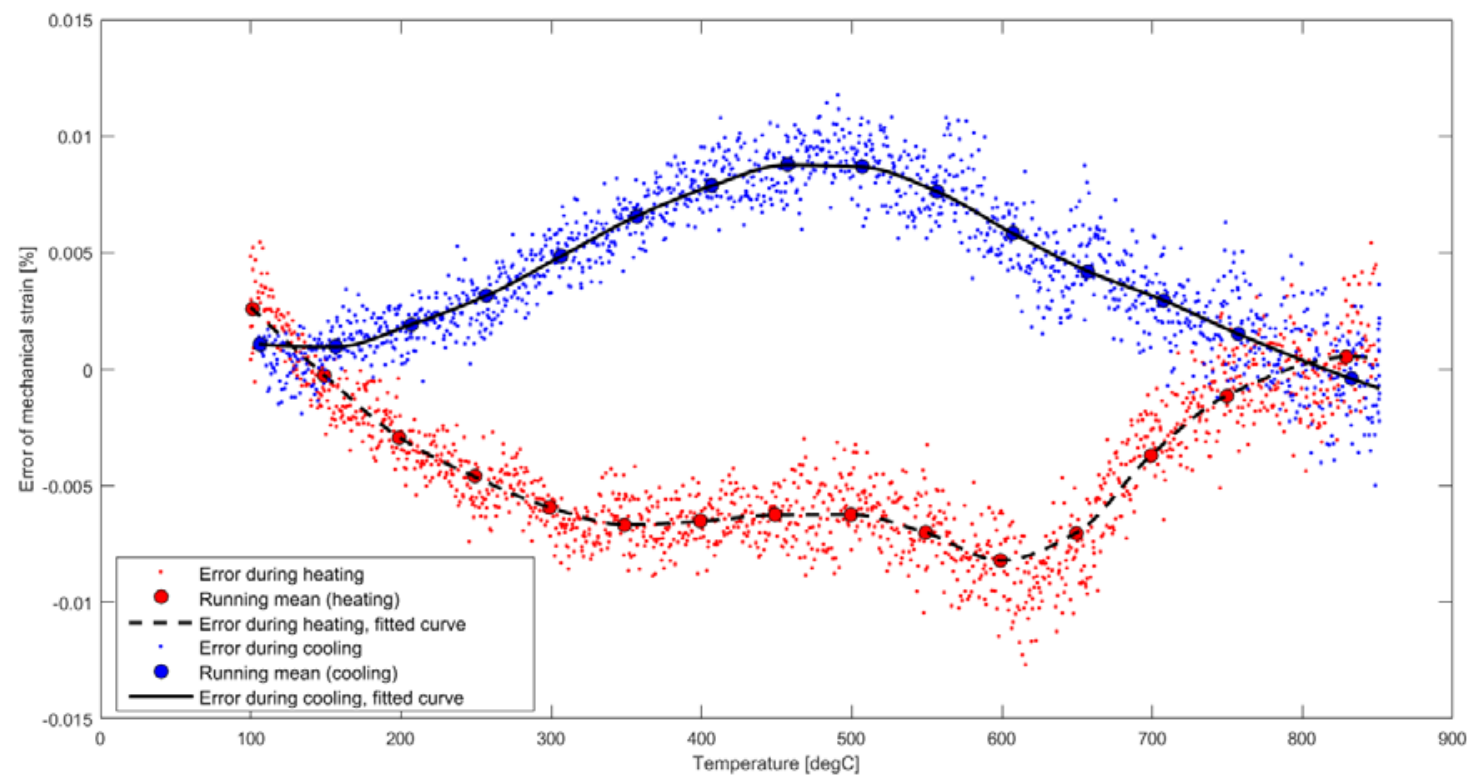

Figure 3 - Error of mechanical strain output by the testing software which is corrected for in postprocesing. The example shown is from Test 2.

\section{2) Characterization of un-cracked specimen stiffness}

a) Correct the thermal strain, based on input from " 1 ”, in order to obtain the correct mechanical strain.

b) Identify characteristic points of each cycle; e.g. start, end, max stress and min stress.

c) Evaluate the stiffness of the un-cracked specimen during unloading $\left(\mathrm{M}_{0, \text { unload}}\right)$, at temperature $\mathrm{T}_{\mathrm{a}}$, see Figure 3a. 
d) Evaluate the relationship between stiffness and temperature during loading of the un-cracked specimen $\left(\mathrm{M}_{0, \mathrm{load}}\right)$. This is done by fitting a polynomial to the loading part of the stress vs mechanical strain curve, see Figure 3b. The polynomial is differentiated to obtain a continuous description of the stiffness vs stress during the loading ramp. For each stress point on the loading ramp, the temperature is known and a stiffness vs temperature plot can thereby be constructed, see Figure 3c. The black dots in Figure 3c represent the stiffness vs temperature data for all the evaluated un-cracked cycles and the red curve is a fitted polynomial used as an average representation of the stiffness vs temperature of the un-cracked specimen.

e) Plot and save the results. 

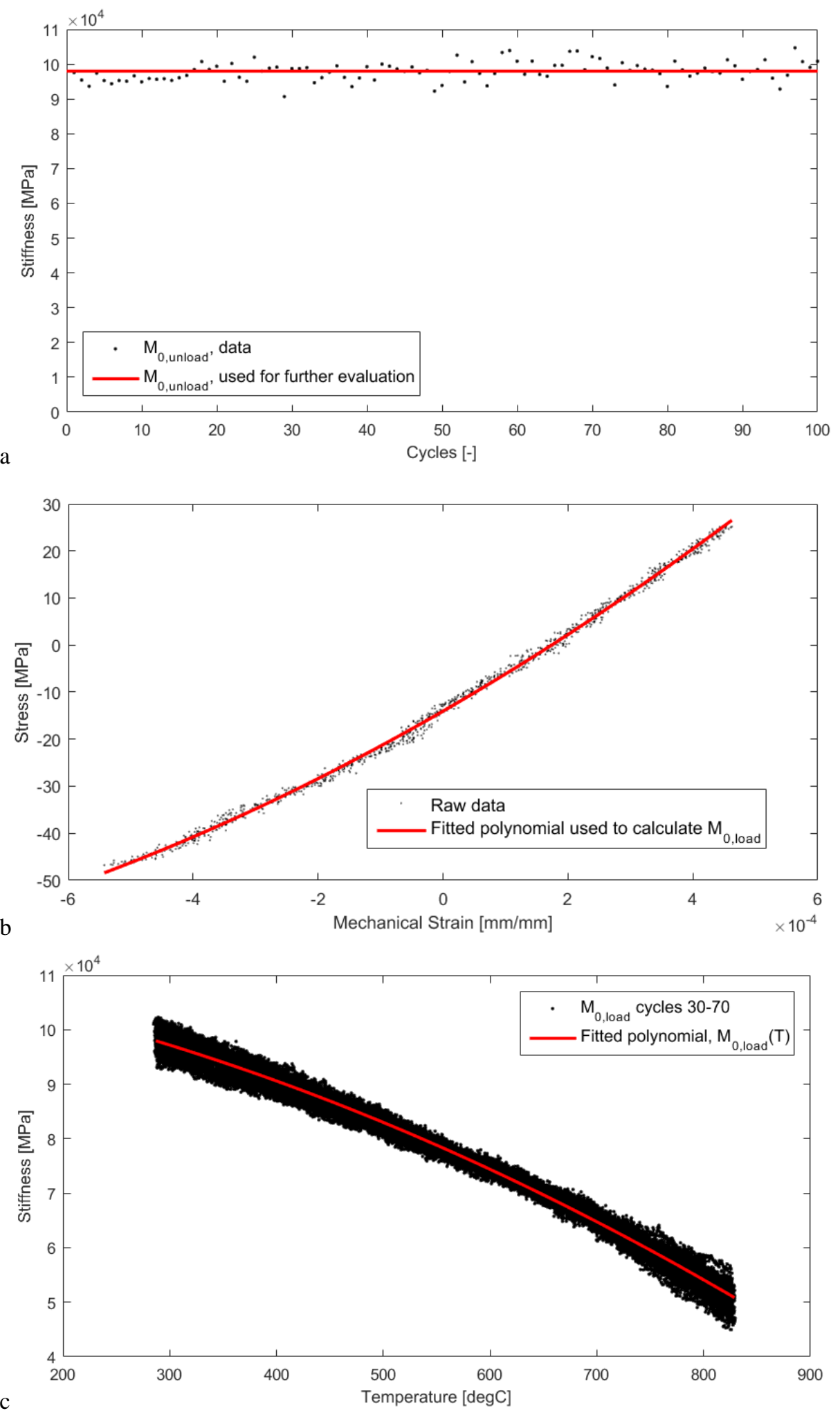

Figure 4: Characterization of uncracked stiffness during TMF loading for Test 2. a: Mo,unload vs cycle number. The red line marks the value manually selected as representative. b: Polynomial fit to the stress-strain loading ramp for one of the cycles used for Mo,load evaluation. c: Mo,load Vs T, evaluated from all fitted polynomials. The red curve is the polynomial fit used in further evaluations, as an average representation of $M_{0, \text { load }}(T)$. 


\section{3) Evaluation of crack length vs cycles}

a) Correct the thermal strain, based on input from "1", in order to obtain the correct mechanical strain.

b) Identify characteristic points of each cycle; e.g. start, end, max stress and min stress.

c) Evaluate the stiffness in each cycle $\left(\mathrm{M}_{\mathrm{i}}\right)$ and calculate the crack length based on Eq. (1).

d) Evaluate the stiffness during loading of the cracked specimen $\left(\mathrm{M}_{\mathrm{i}, \text { load }}\right)$, using secant evaluation applied to points obtained by central moving average filtering of the raw data, see Figure 4a. The filtered points are equally spaced in terms of stress and the spacing is manually set. Use the obtained stiffness during loading to calculate the degree of opening for the loading ramp and extract the crack opening stress, see Figure 4b. Repeat the crack opening evaluation for a specified set of cycles, see Figure 4c. The crack opening force evaluation is further described in section 2.8.2.

e) Plot and save the results. 


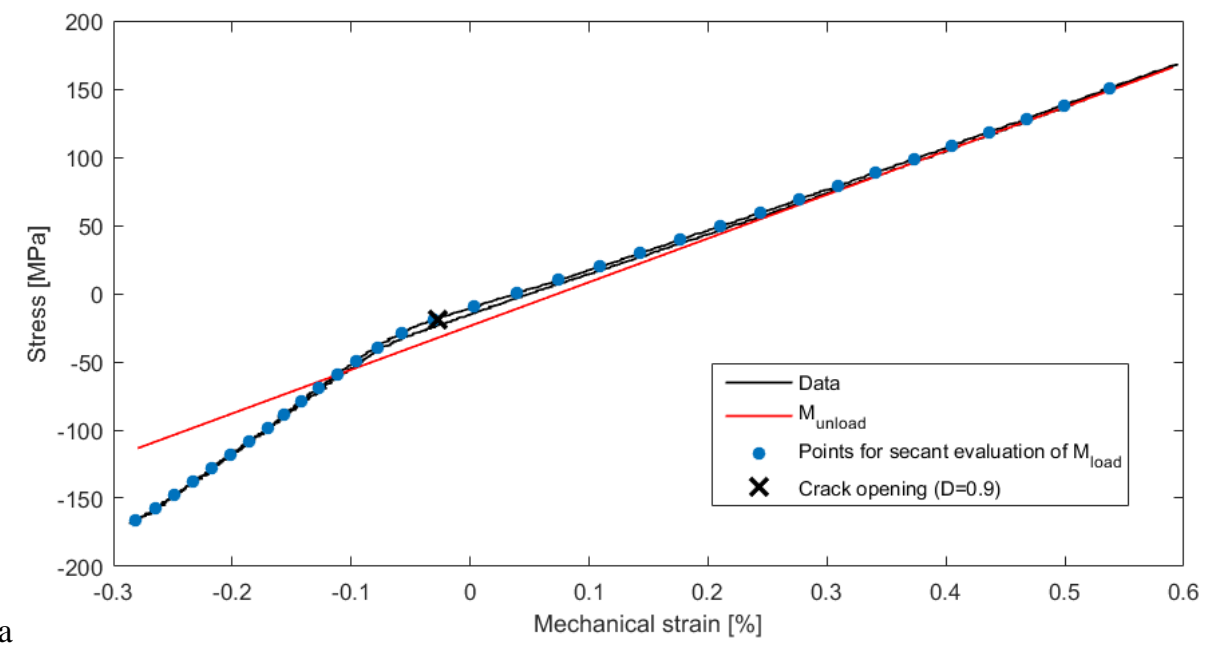

a
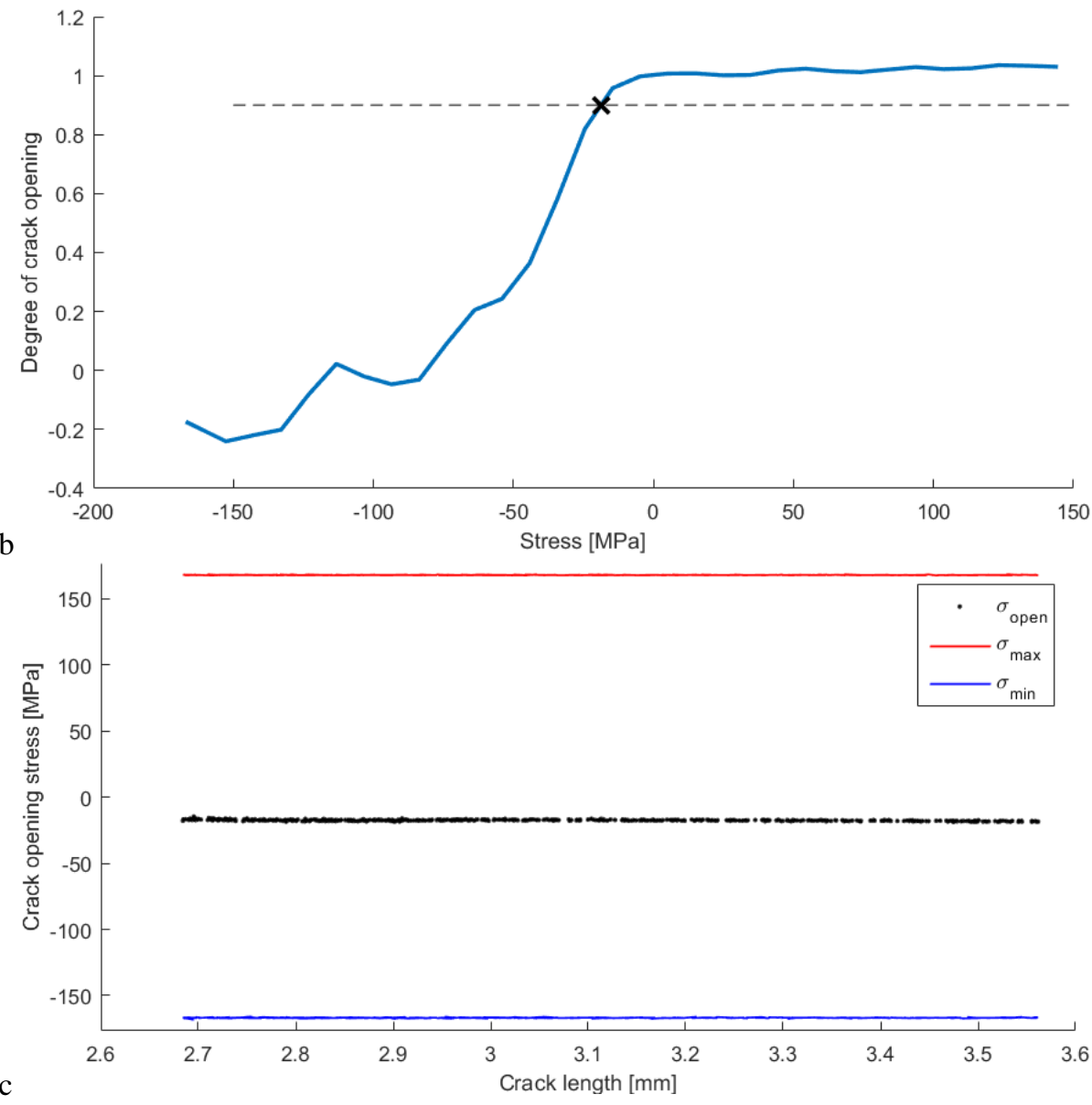

Figure 5: Characterization of crack opening for Test 2, block 09. a: Evaluation of Mload for the cracked specimen in cycle 551 at a crack length of $3.6 \mathrm{~mm}$. Secant evaluation applied to points obtained by central moving average filtering of the raw data. b: Degree of opening vs stress in cycle 551, based on Eq. (3). The crack opening criterion of $D=0.9$ is marked by a dashed line. $c$ : $\sigma_{\text {open }}$ vs crack length for all 551 cycles in Test 2, block 09. This was obtained by repeating "a" and "b" for each cycle. 


\section{4) Evaluation of $\mathbf{d a} / \mathbf{d N}$ vs $\Delta K$}

a) Read data output from “3”.

b) Filter the crack length vs cycles data and evaluate da/dN vs cycles. The filtering algorithm is described in section 2.8.1.

c) Calculate fracture mechanics parameters $\Delta K$ and $\Delta K_{\text {effexp. }}$.

d) Plot to ensure reasonable data filtering and save the results.

\subsubsection{Filtering of crack length data}

The crack length vs cycles raw data contains considerable noise and must therefore be filtered before da/dN can be evaluated. The filtering process is described by a flowchart, see Figure 5. The data filtering process is semiautomatic, in the sense that it requires the test engineer to set the value of the "smoothing parameter" atol and check that the resulting filtered data is in good agreement with the raw data. If necessary, the evaluation is rerun with a manually adjusted value of $\mathrm{a}_{\text {tol }}$. For tests run using the same test set-up, the noise level is similar and consequently only small adjustments of $\mathrm{a}_{\text {tol }}$ are required from test to test. For the present testing $\mathrm{a}_{\text {tol }}$ was typically in the range of $0.01-0.05 \mathrm{~mm}$. For tests with long hold time and high da/dN it is advisable to bypass the pre-filtering step by setting the parameter $\rho_{M A}=0$.

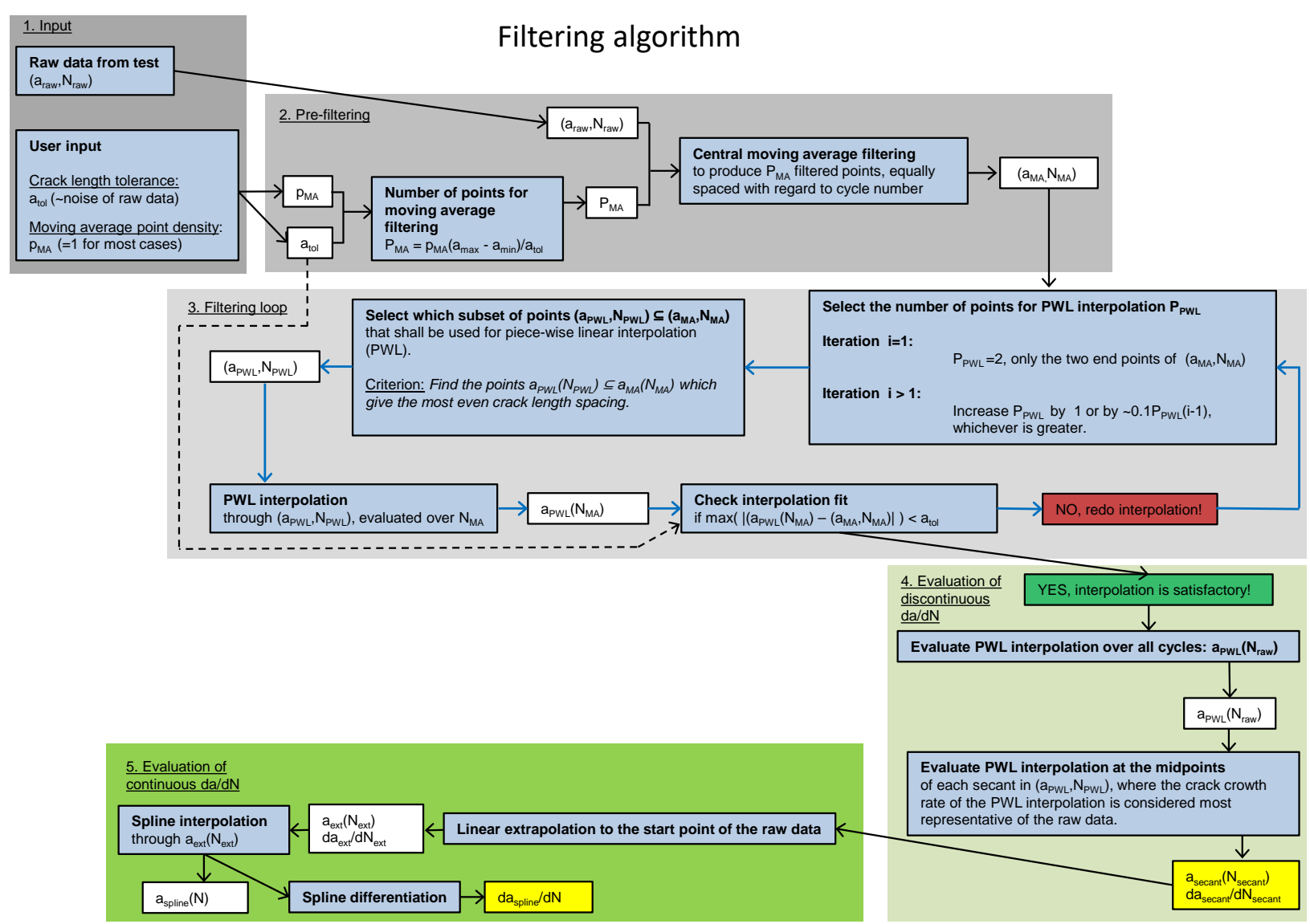

Figure 6 - Algorithm used to filter the raw crack length vs cycles data. 


\subsubsection{Crack opening evaluation}

Different methods to evaluate the crack opening force based on force-displacement data, under isothermal conditions have been investigated by Blandford ${ }^{31}$. To the authors' knowledge there is no established method to evaluate the crack opening force under TMF conditions. A compliance-based method was previously used by Moverare et al. ${ }^{25}$. This method did not take into account the variation in elastic modulus with temperature and for the evaluation of the present testing this resulted in large errors, especially for short cracks. In the present work a new compliance-based method is developed, which does take the temperature dependence of the elastic modulus into account and yields a crack opening force for which the degree of crack opening is well defined. Furthermore, the proposed method does not rely on the assumption of elastic behavior in the entire loading cycle. Elastic behavior is only assumed for the part of the loading ramp where the crack is closed. The method does not require any input of material data, other than the data from the specific test to be evaluated. The method is based on the stiffness determined from the displacement measured by the extensometer. The points between which the displacement is measured are situated far away from the crack tip, see Figure 2b. The effective stress intensity factor range $\Delta K_{\text {eff }}$ is governed by the local opening event at the crack tip. Using this global approach, the apparent crack opening stress based on extensometer measurements is used as an approximation for the stress required for opening at the crack tip: $\Delta K_{\text {eff }} \sim \Delta K_{\text {eff,exp. }}$ The details of the crack opening evaluation method are described below.

\subsubsection{Degree of crack opening}

The relative stiffness decrease of the specimen upon loading in cycle $\mathrm{i}\left(\beta_{\mathrm{i}, \text { load}}\right)$, divided by the relative stiffness decrease for the fully open crack during unloading in cycle i-1 ( $\left.\beta_{\mathrm{i}-1, \text { unload }}\right)$ was used as an indicator of the degree of crack opening. The degree of crack opening in cycle i is denoted $\mathrm{D}_{\mathrm{i}}$, see Eq (3). All parameters used to describe crack opening are described in Table 2.

$D_{i}(\tau)=\frac{\beta_{\text {i,load }}(\tau)}{\beta_{\text {i-1,unload }}}=\frac{1-\frac{M_{\mathrm{i}, \text { load }}(\tau)}{M_{0, \text { load }}\left(T_{i}(\tau)\right)}}{1-\frac{M_{\mathrm{i}-1, \text { unload }}}{M_{0, \text { unload }}}}$
$\tau=\frac{t-t_{i}}{t_{\text {ramp }}}$ 
Table 2 - Parameters used to describe the crack opening.

\begin{tabular}{l|l|l} 
Symbol & Description & Comment \\
\hline $\mathbf{t}$ & Time & Varying within each cycle \\
\hline $\mathbf{t}_{\mathbf{i}}$ & Time at the start of the loading ramp in cycle i & Constant for each cycle \\
\hline $\mathbf{t}_{\text {ramp }}$ & Duration of the loading ramp & Constant for each test \\
\hline $\boldsymbol{\tau}$ & Dimensionless time variable & Varying within each cycle \\
\hline $\mathbf{a}_{\mathbf{i}}$ & Crack length during unloading in cycle i & Constant for each cycle \\
\hline $\mathbf{T}_{\mathbf{i}}$ & Temperature during the loading ramp in cycle i & Varying within each cycle \\
\hline $\mathbf{M}_{\mathbf{i}-\mathbf{1}, \text { unload }}$ & Stiffness during unloading in cycle i-1 & Constant for each cycle \\
\hline $\mathbf{M}_{\mathbf{0}, \text { unload }}$ & $\begin{array}{l}\text { Stiffness of the un-cracked specimen during } \\
\text { unloading }\end{array}$ & Constant for each test \\
\hline $\mathbf{M}_{\mathbf{i}, \text { load }}$ & Stiffness during loading in cycle i & Varying within each cycle \\
\hline $\mathbf{M}_{\mathbf{0}, \mathbf{l o a d}}$ & $\begin{array}{l}\text { Stiffness during loading of the un-cracked } \\
\text { specimen }\end{array}$ & Function of T, evaluated before crack initiation
\end{tabular}

The stiffness during loading of the cracked specimen $\left(\mathrm{M}_{\mathrm{i}, \text { load }}\right)$, is obtained by secant evaluation applied to points obtained by central moving average filtering of the raw data, see Figure 4a. The filtered points are equally spaced in terms of stress and the spacing is manually set. No smoothing of the raw data is done before the moving average filtering. In an ideal case, D ranges from 0 for a fully closed crack to 1 for a fully open crack. In the evaluation code $\mathrm{D}$ is calculated for the entire loading ramp, but it is only considered valid in the lower part of the loading ramp up until the point where the crack is fully open. The evaluation relies on the assumption that the material behaves elastically up until the point when the crack is fully open. Beyond this point, inelastic effects may have an influence on $\mathrm{D}$ and thereby it may no longer provide a useful measure of the degree of crack opening. This has no impact on the aim of the evaluation, which is to find the point on the stress strain curve corresponding to crack opening. It should be emphasized that stiffness vs temperature data must be obtained also for the un-cracked case in the relevant temperature range. Preferably, this is obtained by subjecting the un-cracked specimen to a sufficient number of TMF cycles, where the loading is low enough to avoid any inelastic deformation in the temperature range where the crack opening force is subsequently to be evaluated for the cracked specimen see Figure 3. Considering the variation in measured stiffness from cycle to cycle, the number of cycles shall be high enough to allow the evaluation of a representative average stiffness for the un-cracked specimen.

\subsubsection{Applied crack opening criterion}

As mentioned previously, $\mathrm{D}=1$ corresponds to complete crack opening for the ideal case. However, due to measurement uncertainty D will not reach exactly 1 for all tests. For practical purposes the criterion for crack opening was set at $\mathrm{D}=0.9$ for all tests. This means that the crack opening stress $\sigma_{\text {open }}$ is systematically slightly underestimated and thus that the true effective stress intensity factor range $\Delta K_{\text {eff }}$ is slightly overestimated by $\Delta K_{\text {eff,exp }}$. An example of this overestimation for a particular testing block (Test 8_03) is shown in Figure 6. For this testing block $\mathrm{D}$ did in fact reach 1 in all cycles and thus it was possible to determine the crack opening force based on $\mathrm{D}=1$ 
as a reference. It can be seen in Figure 6 that the usage of the $\mathrm{D}=0.9$ criterion yields an overestimation of $\Delta K_{\text {eff }}$ by $6 \%$ compared to complete crack opening $(D=1)$. Similar overestimations are expected for all tests, except for cases where the evaluation indicates that the crack is open throughout the entire cycle $\left(\sigma_{\text {open }}=\sigma_{\min }\right)$. In such cases the overestimation of $\Delta K_{\text {eff }}$ is expected to be smaller, or even non-existent. The selection of a suitable value of $\mathrm{D}$ for the crack opening criterion is a trade-off between reducing scatter in the determined crack opening force and minimizing the deviation from the force corresponding to complete crack opening. An important aspect of this trade-off is the crack length limit above which crack opening evaluation is possible. Since the scatter of the determined crack opening force decreases with increasing crack length, it is possible to evaluate the present tests using a crack opening criterion higher than 0.9 by limiting the evaluation to longer crack lengths. This was however not wanted in the present case, since this would give a less complete picture of the crack growth behaviour.

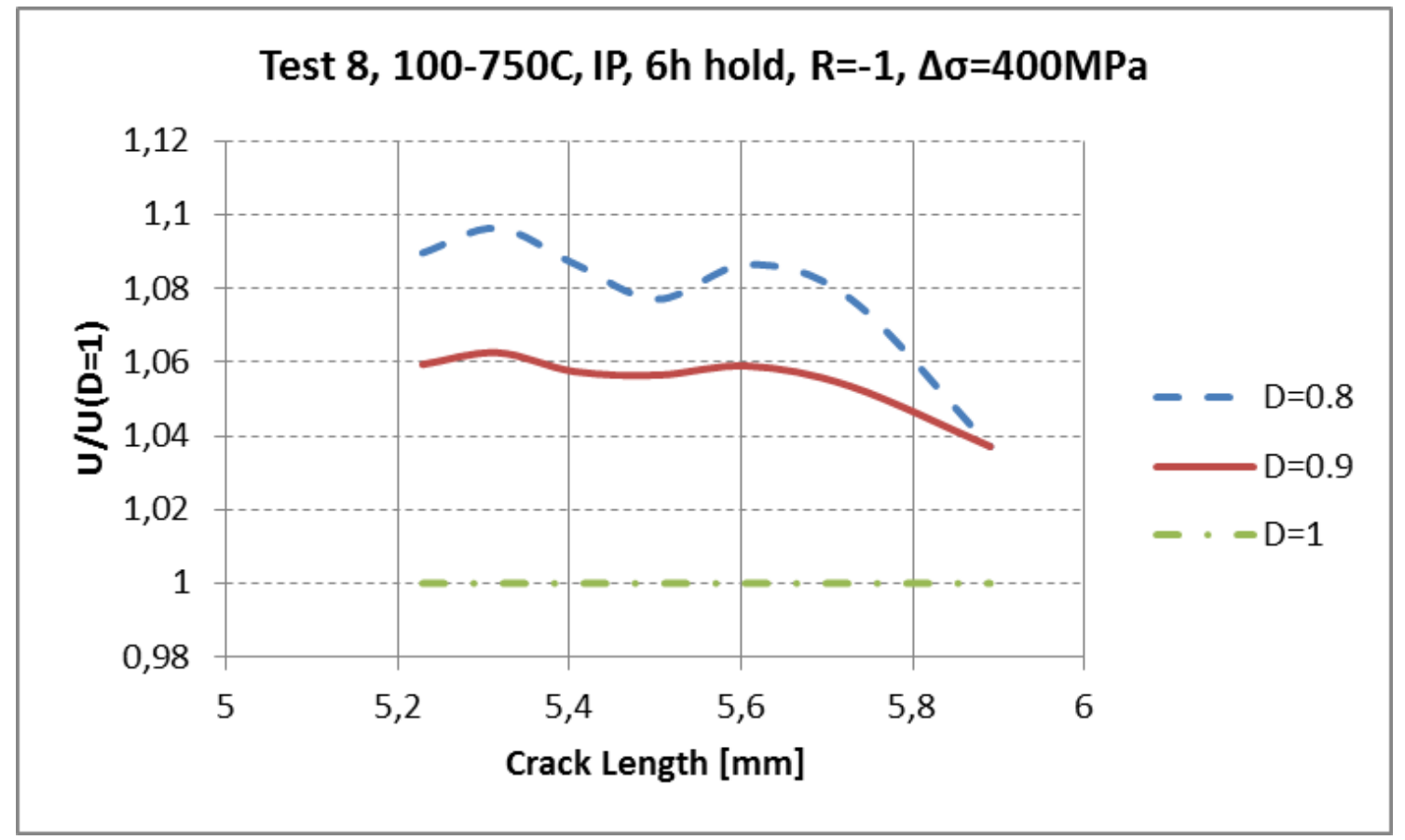

Figure 7 - Example of crack closure evaluation for Test 8. Relative overestimation of the crack closure factor $U$ for different crack opening criteria $D=0.8, D=0.9$ and $D=1$.

\subsubsection{Comparison with compliance offset method modified for TMF}

In ASTM E647, a method is proposed to evaluate the crack opening force in isothermal crack growth tests. The method is based on the compliance offset relative to the open crack compliance ${ }^{32}$. It is recommended to report crack opening force based on compliance offset criteria of $1 \%, 2 \%$ and $4 \%$ relative to the open crack compliance value. The definition of the compliance offset $\left(\mathrm{S}_{\text {offset }}\right)$ for the isothermal case from ASTM E647 is shown in Eq. (3).

$S_{\text {offset }}=\frac{S_{\text {open }}-S_{\text {load }}}{S_{\text {open }}} * 100$

$S=1 / M$

In Eq. (3), $\mathrm{S}_{\text {open }}$ is the open crack compliance and $\mathrm{S}_{\text {load }}$ is the compliance of the specimen during loading. This definition is not applicable to TMF loading, where the elastic modulus varies throughout the cycle. For the sake of comparability with the presently used crack opening evaluation method, the author has modified the definition of compliance offset for TMF conditions, by taking into account the temperature dependence of the stiffness observed 
for the un-cracked specimen. This results in the expression shown in Eq. (5), where the symbols of Eq. (3) have been used.

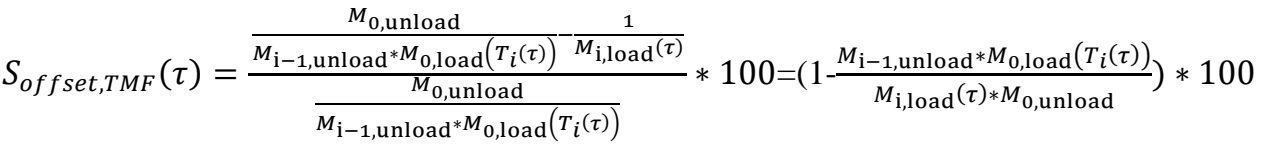

The value of $S_{\text {offset,TMF }}$ depends on the degree of crack opening, but it also depends on the crack length. The purpose of formulating a criterion based on $\mathrm{D}$, was to have a consistent physical interpretation of the state of the crack at the determined crack opening force, regardless of crack length. If the crack opening evaluation would have been based on $\mathrm{S}_{\text {offset,TMF}}$, then the degree of opening at the determined crack opening force would vary with crack length, see Figure 7. A comparison of da/dN vs $\Delta K_{\text {eff }}$ for the different crack opening criteria is shown in Figure 8.

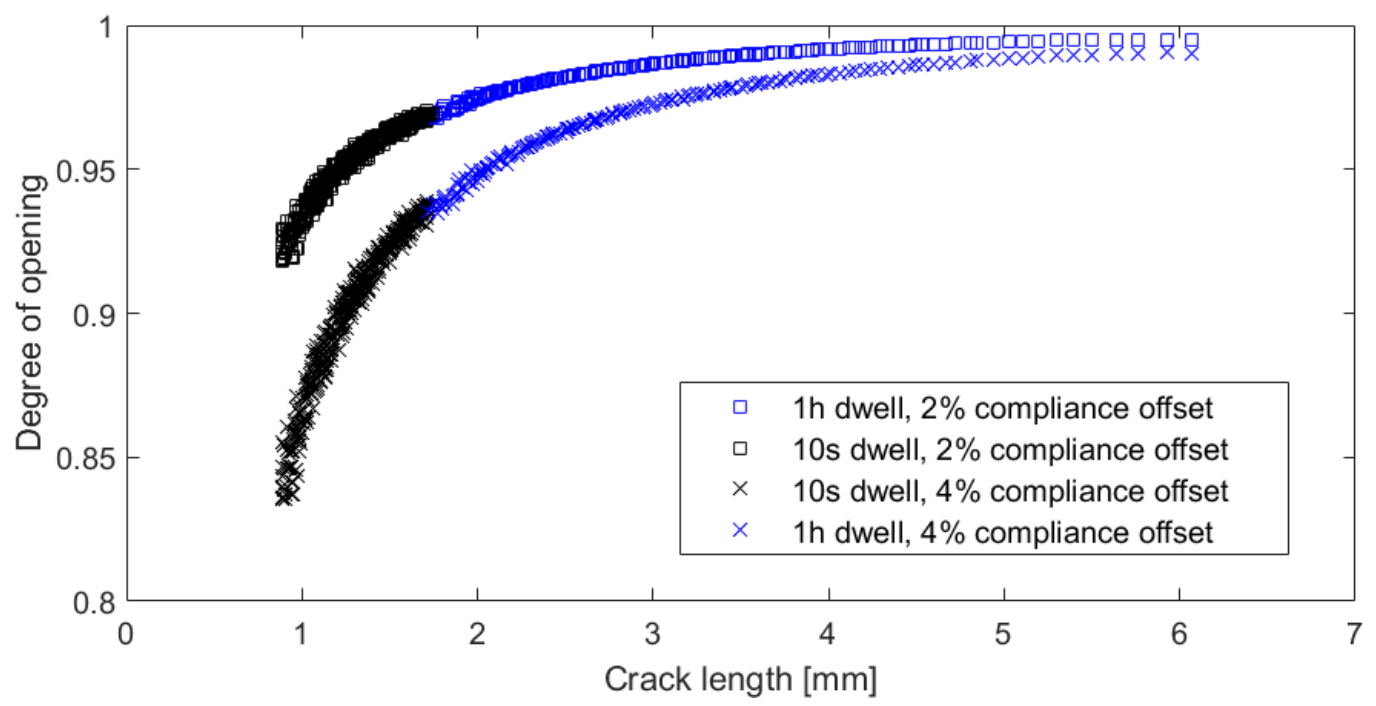

Figure 8 - Comparison of crack opening criteria for test 6. Degree of opening corresponding to $2 \%$ and 4\% compliance offset, plotted against crack length. The definitions of the degree of opening and the compliance offset are given in equations (3) and (5) respectively. 


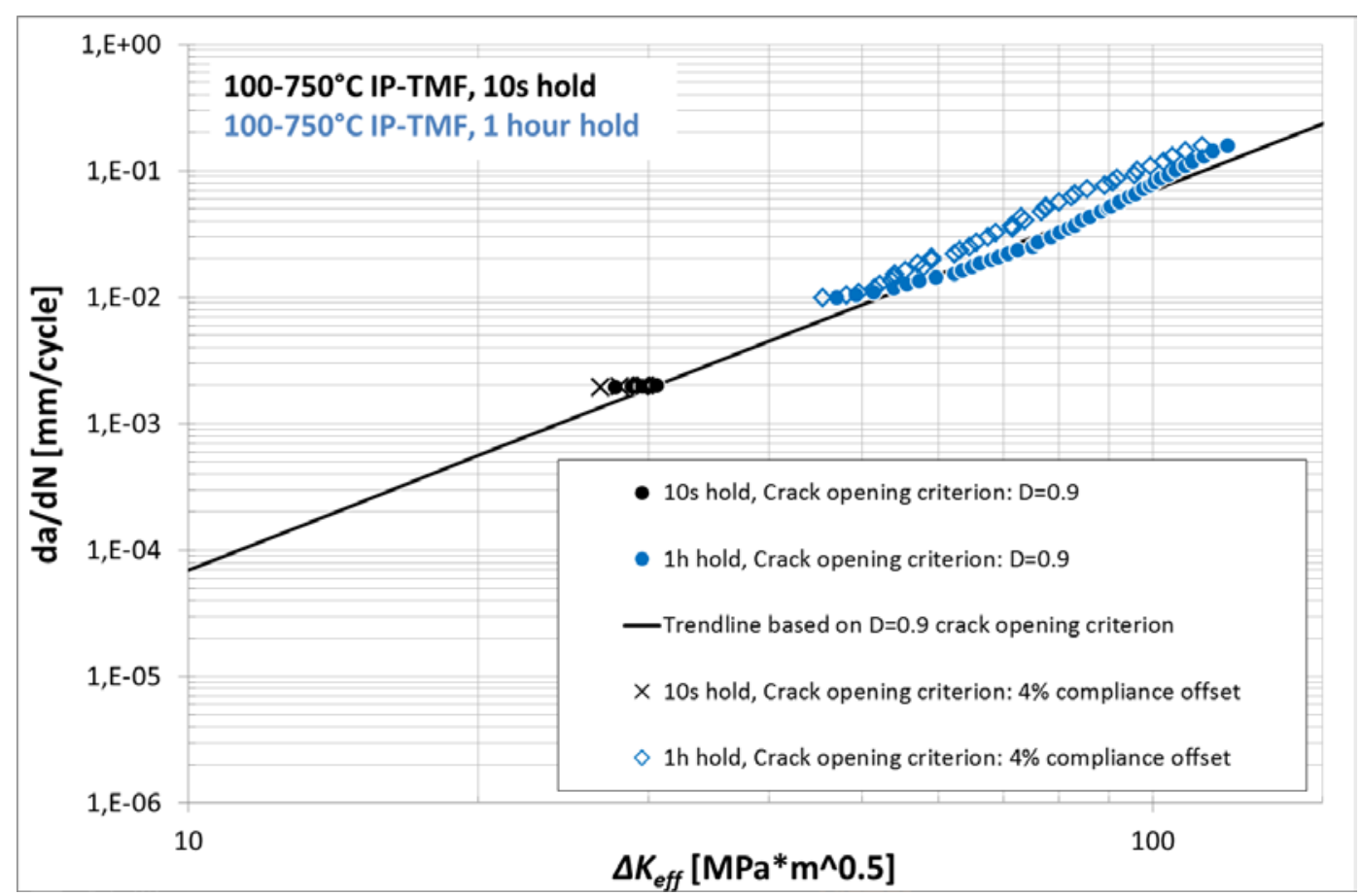

Figure 9 - Crack growth rate vs $\Delta K_{\text {eff }}$ for test 6, using 2 different crack opening criteria. The criterion of $D=0.9$ is the one chosen for the present test evaluation.

\subsection{Fitting of $d a / d N$ vs $\Delta K_{\text {eff }}$ trendlines}

Trendlines were fitted to the crack growth data following Paris law, based on the experimentally determined effective stress intensity factor range $\Delta K_{\text {effexp }}$, see Eq. (6).

$\frac{\mathrm{d} a}{\mathrm{~d} N}=C \cdot \Delta K_{e f f, \exp ^{m}}$

In Eq. (6), da/dN is the crack growth rate and $C$ and $m$ are fitting parameters. For OP-TMF, one trendline was fitted to all tests. For IP-TMF, one trendline was fitted to tests with $\mathrm{T}_{\max }=750^{\circ} \mathrm{C}$ and one trendline was fitted to tests with $\mathrm{T}_{\max }=850^{\circ} \mathrm{C}$. The fitting was done by manual optimization of the fitting parameters. 


\subsection{IP-TMF and high temperature isothermal fatigue}

The crack growth rates during IP-TMF and isothermal testing at $\mathrm{T}_{\max }=750^{\circ} \mathrm{C}$ and $\mathrm{T}_{\max }=850^{\circ} \mathrm{C}$ are shown in Figure 9 and Figure 10. There is no significant difference in crack growth rate between IP-TMF testing and isothermal testing at the maximum temperature. During IP TMF at R=-1, with a maximum temperature of $750^{\circ} \mathrm{C}$ or $850^{\circ} \mathrm{C}$ the crack growth rate vs $\Delta K$ is increased if a hold time of $1 \mathrm{~h}$ or $6 \mathrm{~h}$ is applied at maximum load, see Figure 9 . For the other tests, run at $\mathrm{R}=-1$, the increase of the crack growth rate is approximately the same for $1 \mathrm{~h}$ hold time as for $6 \mathrm{~h}$ hold time. If the hold time influence were due to creep crack growth or oxidation damage ahead of the crack tip, one would expect a higher crack growth rate for $6 \mathrm{~h}$ hold time than for $1 \mathrm{~h}$ hold time ${ }^{21}$. This suggests that the hold time influence is neither dominated by creep crack growth during the hold time, nor by oxidation damage ahead of the crack tip. If the crack growth rate is instead plotted vs the effective stress intensity factor range $\Delta K_{\text {eff,exp }}$, it can be seen that the test data collapses along one trendline for $\mathrm{T}_{\max }=750^{\circ} \mathrm{C}$ and one trendline for $\mathrm{T}_{\max }=850^{\circ} \mathrm{C}$, regardless of the hold time or R-ratio, se Figure 10. These manually fitted trendlines have the same exponent, $\mathrm{m}$ and a moderate factor 2 difference in the coefficient, C. The hold time apparently causes the crack to remain open during a larger part of the loading cycle, thus increasing the effective stress intensity factor range. The crack closure factors for the IP-TMF tests are shown in Figure 11 . At $850^{\circ} \mathrm{C}$ and $\mathrm{R}=-1$, a hold time of $1 \mathrm{~h}$ is enough to completely avoid crack closure in any part of the cycle, see Figure $11 \mathrm{~b}$. At $750^{\circ} \mathrm{C}$ and $\mathrm{R}=-1$ with hold times of $1 \mathrm{~h}$ or $6 \mathrm{~h}$, crack closure can still be observed but the crack closure level is significantly decreased, see Figure 11a. Crack tip blunting by local creep deformation seems like a reasonable explanation for the observed behaviour. It appears that the crack growth of the IP-TMF tests with a load ratio of $\mathrm{R}=-1$ may be regarded as purely cycle dependent, with an indirect

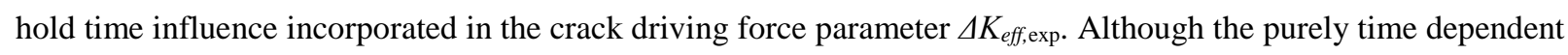
contribution to the crack growth rate is negligible in these particular tests, this is not expected to be the case at higher stress ratios. Previously reported isothermal testing of the same alloy at a stress ratio of $\mathrm{R}=0.1$ has indicated that there is in fact a purely hold time dependent contribution to the crack growth rate at $750{ }^{\circ} \mathrm{C}^{27}$. The stress ratio of the present tests was chosen to be representative of the service conditions experienced by a gas turbine blade, with deformation controlled loading and substantial mean stress relaxation occurring before potential crack initiation. 


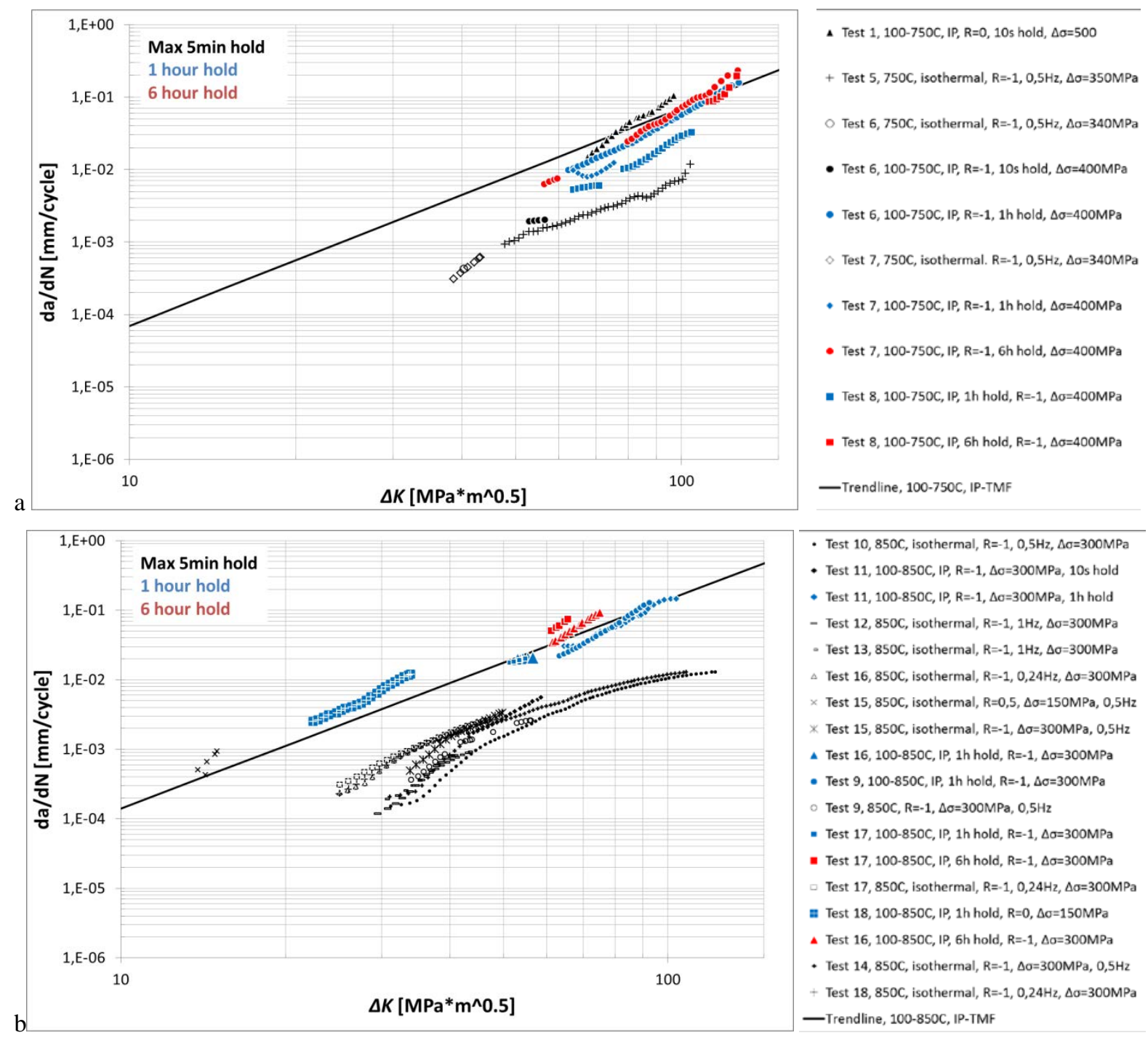

Figure 10 - Crack growth rate vs $\Delta \mathrm{K}$ during IP-TMF and isothermal fatigue testing at the maximum temperature. a: $100-750^{\circ} \mathrm{C}$, b: $100-850^{\circ} \mathrm{C}$. 


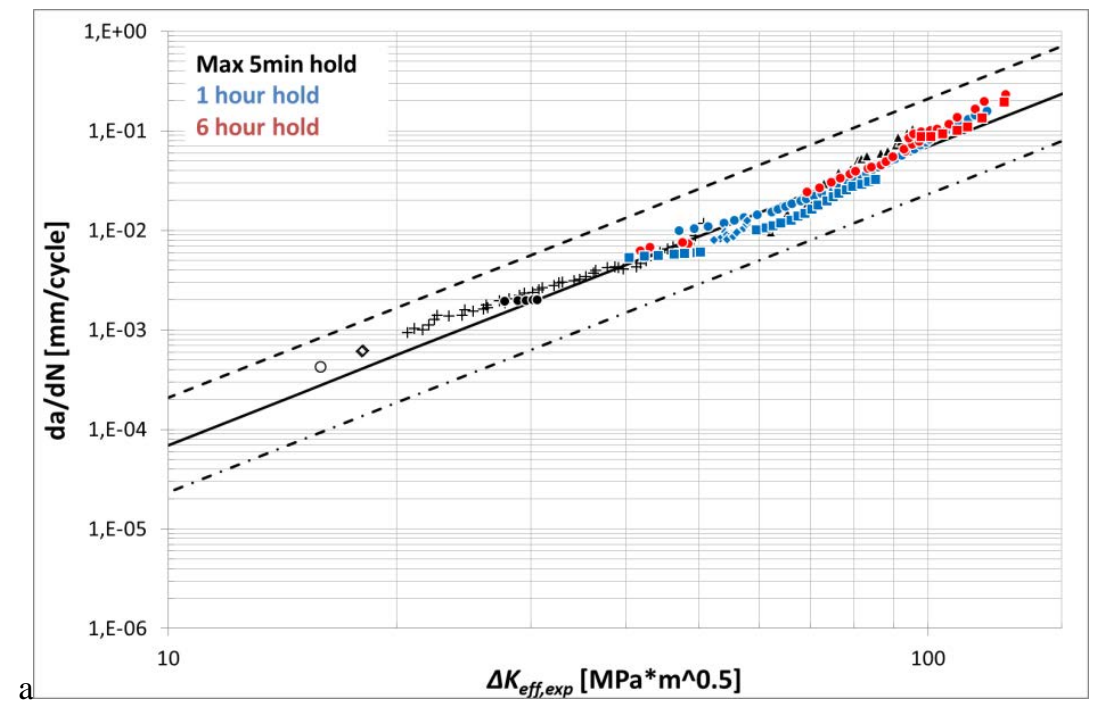

- Test $1,100-750 C, I P, R=0,10$ s hold, $\Delta \sigma=500$

Test 5, 750C, isothermal, $R=-1,0,5 \mathrm{~Hz}, \Delta \sigma=350 \mathrm{MPa}$

Test $6,750 \mathrm{C}$, isothermal, $\mathrm{R}=-1,0,5 \mathrm{~Hz}, \Delta \sigma=340 \mathrm{MPa}$

- Test 6, 100-750C, IP, $R=-1,10$ s hold, $\triangle \sigma=400 \mathrm{MPa}$

- Test $6,100-750 C, I P, R=-1,1 \mathrm{~h}$ hold, $\triangle \sigma=400 \mathrm{MPa}$

Test 7, 750C, isothermal. $\mathrm{R}=-1,0,5 \mathrm{~Hz}, \Delta \sigma=340 \mathrm{MPa}$

- Test $7,100-750 C, I P, R=-1,1 \mathrm{~h}$ hold, $\triangle \sigma=400 \mathrm{MPa}$

- Test 7, 100-750C, IP, $R=-1,6$ h hold, $\Delta \sigma=400 \mathrm{MPa}$

- Test $8,100-750 \mathrm{C}, \mathrm{IP}, 1 \mathrm{~h}$ hold, $\mathrm{R}=-1, \Delta \sigma=400 \mathrm{MPa}$

- Test $8,100-750 \mathrm{C}, \mathrm{IP}, 6 \mathrm{~h}$ hold, $\mathrm{R}=-1, \Delta \sigma=400 \mathrm{MPa}$

- 100-750C IP-TMF, upper bound

-Trendline, 100-750C, IP-TMF

$\cdot-100-750$ C IP-TMF, lower bound

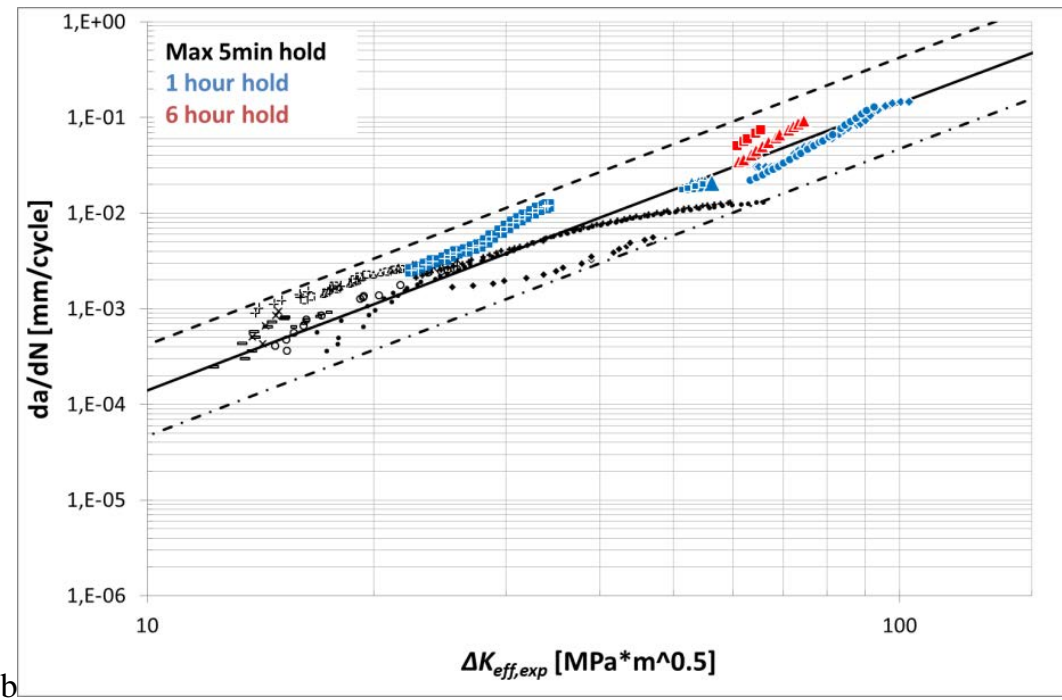

- Test $10,850 \mathrm{C}$, isothermal, $\mathrm{R}=-1,0,5 \mathrm{~Hz}, \Delta \sigma=300 \mathrm{MPa}$

- Test $11,100-850 \mathrm{C}, \mathrm{IP}, \mathrm{R}=-1, \Delta 0=300 \mathrm{MPa}, 10 \mathrm{~s}$ hold

- Test $11,100-850 \mathrm{C}, \mathrm{IP}, \mathrm{R}=-1, \Delta \sigma=300 \mathrm{MPa}$, $1 \mathrm{~h}$ hold

- Test $12,850 \mathrm{C}$, isothermal, $R=-1,1 \mathrm{~Hz}, \Delta \mathrm{O}=300 \mathrm{MPa}$

- Test $13,850 \mathrm{C}$, isothermal, $R=-1,1 \mathrm{~Hz}, \Delta \mathrm{O}=300 \mathrm{MPa}$

$\Delta$ Test $16,850 \mathrm{C}$, isothermal, $\mathrm{R}=-1,0,24 \mathrm{~Hz}, \triangle \mathrm{v}=300 \mathrm{MPa}$

$\times$ Test $15,850 \mathrm{C}$, isothermal, $\mathrm{R}=0,5, \triangle \sigma=150 \mathrm{MPa}, 0,5 \mathrm{~Hz}$

* Test $15,850 \mathrm{C}$, isothermal, $\mathrm{R}=1, \Delta \sigma=300 \mathrm{MPa}, 0,5 \mathrm{~Hz}$

A Test 16, 100-850C, IP, 1 h hold, $R=-1, \triangle \sigma=300 \mathrm{MPa}$

- Test 9, 100-850C, IP, $1 \mathrm{~h}$ hold, R=-1, $\Delta \sigma=300 \mathrm{MPa}$

- Test $9,850 \mathrm{C}, \mathrm{R}=-1, \Delta \sigma=300 \mathrm{MPa}, 0,5 \mathrm{~Hz}$

- Test $17,100-850 \mathrm{C}, \mathrm{IP}, 1 \mathrm{~h}$ hold, R=-1, $\Delta \sigma=300 \mathrm{MPa}$

- Test $17,100-850 \mathrm{C}, \mathrm{IP}, 6 \mathrm{~h}$ hold, $\mathrm{R}=-1, \Delta \sigma=300 \mathrm{MPa}$

- Test $17,850 \mathrm{C}$, isothermal, $R=-1,0,24 \mathrm{~Hz}, \Delta \sigma=300 \mathrm{MPa}$

"n Test $18,100-850 \mathrm{C}, \mathrm{IP}, 1 \mathrm{~h}$ hold, $\mathrm{R}=0, \Delta \mathrm{\sigma}=150 \mathrm{MPa}$

$\Delta$ Test $16,100-850 \mathrm{C}, \mathrm{IP}, 6 \mathrm{~h}$ hold, $R=-1, \Delta \mathrm{O}=300 \mathrm{MPa}$

- Test $14,850 \mathrm{C}$, isothermal, $\mathrm{R}=-1, \Delta \mathrm{O}=300 \mathrm{MPa}, 0,5 \mathrm{~Hz}$

+ Test $18,850 \mathrm{C}$, isothermal, $\mathrm{R}=-1,0,24 \mathrm{~Hz}, \Delta \mathrm{v}=300 \mathrm{MPa}$

- - 100-850C IP-TMF, upper bound

-Trendline, 100-850C, IP-TMF

- - -100-850C IP-TMF, lower bound

Figure 11 - Crack growth rate vs $\Delta \mathrm{K}_{\text {eff, exp }}$ during IP-TMF and isothermal fatigue testing at the maximum temperature. a: $100-750^{\circ} \mathrm{C}$, b: $100-850^{\circ} \mathrm{C}$. 


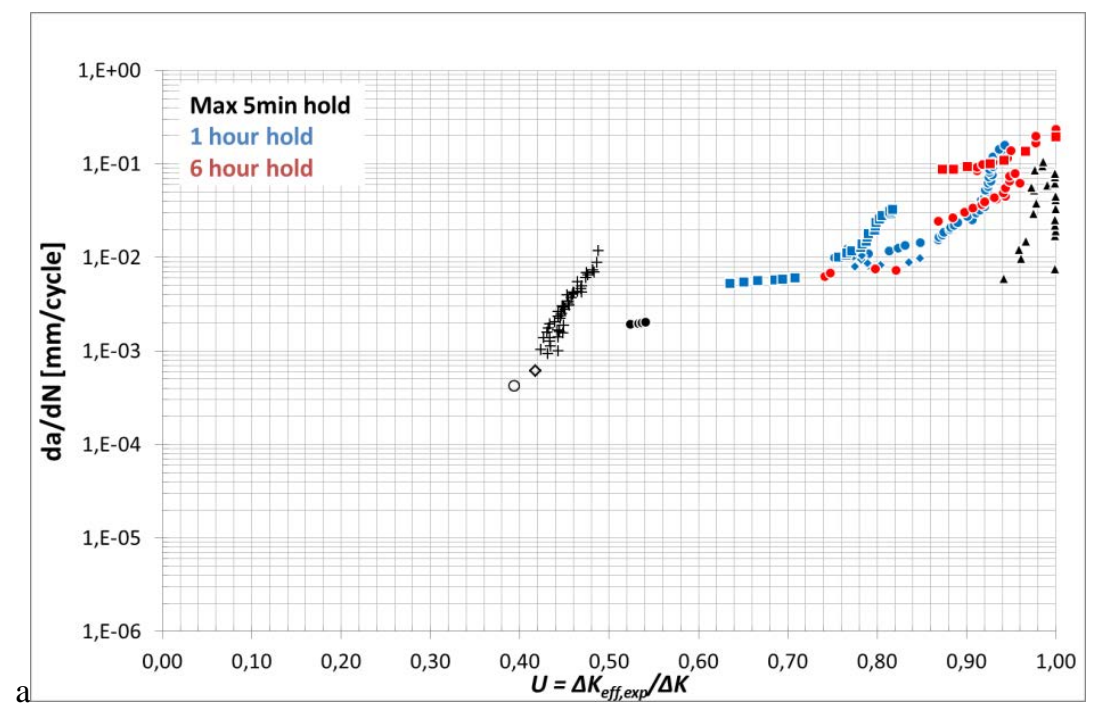

$\Delta$ Test $1,100-750 C, I P, R=0,10$ s hold, $\Delta \sigma=500$

+ Test 5, 750C, isothermal, $\mathrm{R}=-1,0,5 \mathrm{~Hz}, \Delta \sigma=350 \mathrm{MPa}$

- Test $6,750 \mathrm{C}$, isothermal, $\mathrm{R}=-1,0,5 \mathrm{~Hz}, \Delta \sigma=340 \mathrm{MPa}$

- Test 6, 100-750C, IP, R=-1, 10s hold, $\triangle \mathrm{o}=400 \mathrm{MPa}$

- Test $6,100-750 C, I P, R=-1,1 \mathrm{~h}$ hold, $\triangle \sigma=400 M P a$

- Test 7, 750C, isothermal. $\mathrm{R}=-1,0,5 \mathrm{~Hz}, \Delta \mathrm{\sigma}=340 \mathrm{MPa}$

- Test 7, 100-750C, IP, R=-1, $1 \mathrm{~h}$ hold, $\triangle 0=400 \mathrm{MPa}$

- Test 7, 100-750C, IP, $R=-1,6 \mathrm{~h}$ hold, $\triangle \sigma=400 \mathrm{MPa}$

- Test $8,100-750 \mathrm{C}, \mathrm{IP}, 1 \mathrm{~h}$ hold, $\mathrm{R}=-1, \Delta \sigma=400 \mathrm{MPa}$

- Test 8, 100-750C, IP, 6h hold, $R=-1, \triangle \sigma=400 \mathrm{MPa}$

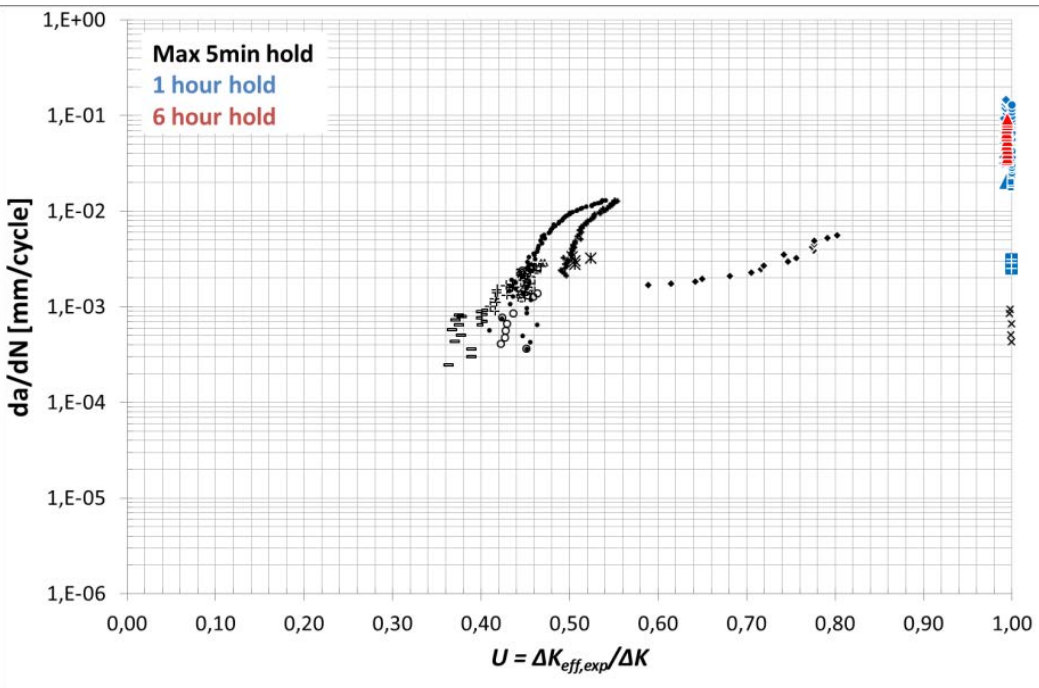

- Test $10,850 \mathrm{C}$, isothermal, $\mathrm{R}=-1,0,5 \mathrm{~Hz}, \Delta \sigma=300 \mathrm{MPa}$

- Test $11,100-850 C, I P, R=-1, \Delta \sigma=300 \mathrm{MPa}$, 10 s hold

- Test $11,100-850 \mathrm{C}, \mathrm{IP}, \mathrm{R}=-1, \Delta \sigma=300 \mathrm{MPa}, 1 \mathrm{~h}$ hold

- Test $12,850 \mathrm{C}$, isothermal, $\mathrm{R}=-1,1 \mathrm{~Hz}, \Delta \sigma=300 \mathrm{MPa}$

- Test $13,850 \mathrm{C}$, isothermal, $R=1,1 \mathrm{~Hz}, \Delta \mathrm{\sigma}=300 \mathrm{MPa}$

$\triangle$ Test $16,850 \mathrm{C}$, isothermal, $\mathrm{R}=-1,0,24 \mathrm{~Hz}, \Delta \sigma=300 \mathrm{MPa}$

$\times$ Test $15,850 \mathrm{C}$, isothermal, $R=0,5, \triangle \sigma=150 \mathrm{MPa}, 0,5 \mathrm{~Hz}$

X. Test $15,850 \mathrm{C}$, isothermal, $\mathrm{R}=-1, \Delta \sigma=300 \mathrm{MPa}, 0,5 \mathrm{~Hz}$

$\triangle$ Test $16,100-850 \mathrm{C}$, IP, $1 \mathrm{~h}$ hold, $R=-1, \Delta \mathrm{o}=300 \mathrm{MPa}$

- Test $9,100-850 \mathrm{C}, \mathrm{IP}, 1 \mathrm{~h}$ hold, $\mathrm{R}=-1, \triangle \sigma=300 \mathrm{MPa}$

- Test $9,850 \mathrm{C}, \mathrm{R}=-1, \Delta \sigma=300 \mathrm{MPa}, 0,5 \mathrm{~Hz}$

- Test 17, 100-850C, IP, $1 \mathrm{~h}$ hold, $R=1, \Delta \mathrm{\sigma}=300 \mathrm{MPa}$

- Test 17, 100-850C, IP, $6 \mathrm{~h}$ hold, R=-1, $\Delta$ o $=300 \mathrm{MPa}$

口 Test $17,850 \mathrm{C}$, isothermal, $R=-1,0,24 \mathrm{~Hz}, \Delta \sigma=300 \mathrm{MPa}$

\# Test $18,100-850 \mathrm{C}, \mathrm{IP}$, 1h hold, $\mathrm{R}=0, \Delta \sigma=150 \mathrm{MPa}$

$\Delta$ Test $16,100-850 \mathrm{C}, \mathrm{IP}, 6 \mathrm{~h}$ hold, $\mathrm{R}=-1, \Delta \mathrm{\sigma}=300 \mathrm{MPa}$

- Test $14,850 \mathrm{C}$, isothermal, $R=-1, \triangle 0=300 \mathrm{MPa}, 0,5 \mathrm{~Hz}$

+ Test $18,850 \mathrm{C}$, isothermal, $\mathrm{R}=-1,0,24 \mathrm{~Hz}, \Delta \sigma=300 \mathrm{MPa}$

Figure 12 - Crack growth rate vs experimentally observed crack closure factor during IP-TMF and isothermal fatigue testing the maximum temperature. a: $100-750^{\circ} \mathrm{C}, \mathrm{b}: 100$ $850^{\circ} \mathrm{C}$. 


\subsection{OP-TMF and low temperature isothermal fatigue}

During OP TMF, the crack growth rates of the present tests were rather insensitive to the maximum temperature and also to the length of hold time at maximum temperature. The maximum temperature of the OP-TMF tests was either $750^{\circ} \mathrm{C}$ or $850^{\circ} \mathrm{C}$ and hold times of 10 s and $1 \mathrm{~h}$ were used. For all OP-TMF tests the crack growth rates vs $\Delta K_{\text {eff, exp }}$ collapse along the same trendline, within a factor 3 scatterband, see Figure 12b. If the crack growth rate is plotted vs the full range of $\Delta K$, the data does not collapse in the same way and for some tests the crack growth rate decreases with increasing $\Delta K$, see Figure 12a. The crack closure factor for the OP-TMF tests is shown in Figure 13. Isothermal testing at $100^{\circ} \mathrm{C}$ was also performed and the crack growth rates vs $\Delta K_{\text {eff,exp }}$ fall below the scatterband for OP-TMF, even though the actual advancement of the crack presumably occurs at the same temperature as in the OP-TMF tests. It should be mentioned that the specimens tested isothermally at $100^{\circ} \mathrm{C}$ have first been subjected to precracking at $850^{\circ} \mathrm{C}$. The total amount of time spent at $850^{\circ} \mathrm{C}$ is however longer for the OP-TMF tests.

Microstructural investigations revealed clear differences between specimens tested under OP-TMF and isothermally at $100^{\circ} \mathrm{C}$, see Figure 14 . Along the notch flanks, close to the corners of the notch of specimen SEN-1, the stresses are assumed to have been negligibly low during the testing. The microstructure in this region was therefore considered as unaffected by the mechanical loading during the test, thus only reflecting the thermal exposure. Figure 14a and c show the microstructures in regions of low stress for $100^{\circ} \mathrm{C}$ isothermal testing and $100-850^{\circ} \mathrm{C}$ OP-TMF respectively. For the isothermal test at $100^{\circ} \mathrm{C}$, the primary $\gamma^{\prime}$ particles have retained their cuboidal shape during the test and secondary $\gamma^{\prime}$ particles are remaining within the $\gamma$ channels. In the case of OP-TMF the primary $\gamma^{\prime}$ particles have been rounded as a result of thermal exposure at $850^{\circ} \mathrm{C}$ and the secondary $\gamma^{\prime}$ particles have been dissolved or coarsened. In the crack tip region even larger differences can be seen between the $100^{\circ} \mathrm{C}$ isothermal test and the $100-850^{\circ} \mathrm{C}$ OP-TMF test, see Figure $14 \mathrm{~b}$ and $\mathrm{d}$. In the $100^{\circ} \mathrm{C}$ test the primary $\gamma^{\prime}$ particles are cuboidal, with sharp edges and secondary $\gamma^{\prime}$ particles can be seen within the $\gamma$ channels. In the $100-850^{\circ} \mathrm{C}$ OP-TMF test, the primary $\gamma^{\prime}$ particles are rounded with rough and diffuse edges, apparently in the process of dissolving. Recrystallization can be seen within the $\gamma$ phase. The dissolution of $\gamma^{\prime}$ and recrystallization at the crack tip is a likely explanation for the observed difference in crack growth rate between $100^{\circ} \mathrm{C}$ isothermal tests and OP-TMF tests. Recrystallization has been reported as an important damage mechanism in OP-TMF tests on smooth single crystal specimens $\mathbf{s}^{5,16,33}$. Kraemer et al. have proposed a crack growth model for conventionally cast polycrystalline superalloys which incorporates the influence of $\gamma^{\prime}$ depletion on the crack growth rate ${ }^{11}$. In this model, the $\gamma^{\prime}$ depletion is considered as purely oxidation driven. This would suggest a strong influence of maximum temperature and time. In the present OP-TMF testing large differences would be expected between tests at maximum temperatures of $750^{\circ} \mathrm{C}$ and $850^{\circ} \mathrm{C}$ and likewise between tests with $10 \mathrm{~s}$ dwell and tests with $1 \mathrm{~h}$ dwell. Since the crack growth rates of the present tests are insensitive to maximum temperature and hold time, it appears that the $\gamma^{\prime}$ dissolution is not governed by oxidation. In regions of high dislocation density, dissolution of $\gamma^{\prime}$ and subsequent recrystallization, has been observed by Kontis et al., at temperatures as low as $750^{\circ} \mathrm{C}^{10,34}$. The proposed explanation for the $\gamma^{\prime}$ dissolution at such low temperature was that $\mathrm{Cr}$ and $\mathrm{Co}$ segregated to dislocations and diffused along them via pipe diffusion and that the resulting local chemical inhomogeneity enabled the dissolution of $\gamma^{\prime}$. This explanation was supported by atom probe tomography, which confirmed the segregation of $\mathrm{Co}$ and $\mathrm{Cr}$ at dislocations. 


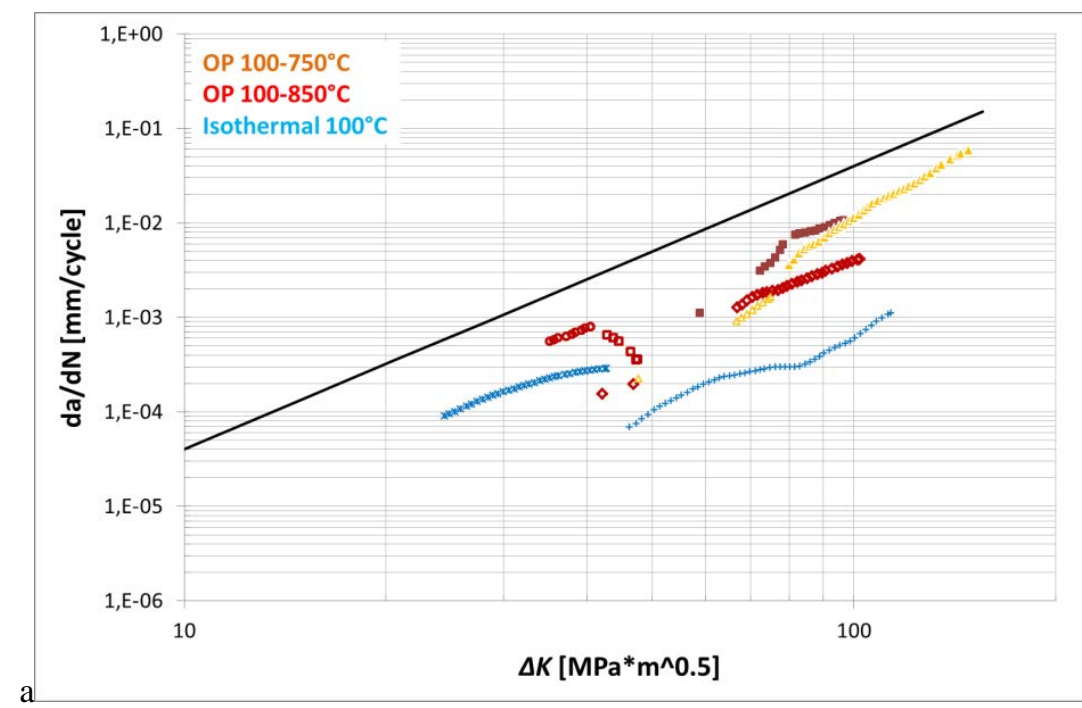

- Test 2, 100-850C, OP, $1 \mathrm{~h}$ hold, $\mathrm{R}=-1, \Delta \mathrm{g}=336 \mathrm{MPa}$

- Test $2,100-850 \mathrm{C}, \mathrm{OP}, 10$ s hold, $R=-1, \triangle \mathrm{O}=280 \mathrm{MPa}$

- Test $3,100-850 \mathrm{C}, \mathrm{OP}, 10$ s hold, $R=-1, \Delta 0=300 \mathrm{MPa}$

Test $4,100-750 \mathrm{C}, \mathrm{OP}, 10$ s hold, $\mathrm{R}=-1, \Delta \sigma=350 \mathrm{MPa}$

Test $4,100-750 \mathrm{C}, \mathrm{OP}, 1 \mathrm{~h}$ hold, $\mathrm{R}=-1, \Delta \mathrm{\sigma}=350 \mathrm{MPa}$

+ Test $12,100 \mathrm{C}, \mathrm{R}=-1, \Delta \sigma=300 \mathrm{MPa}$

$\times$ Test $13,100 \mathrm{C}, \mathrm{R}=0, \Delta \sigma=150 \mathrm{MPa}$

- Test $15,100-850 \mathrm{C}, \mathrm{OP}, 10 \mathrm{~s}$ hold, $R=0, \Delta \sigma=150 \mathrm{MPa}$

—Trendline, OP-TMF

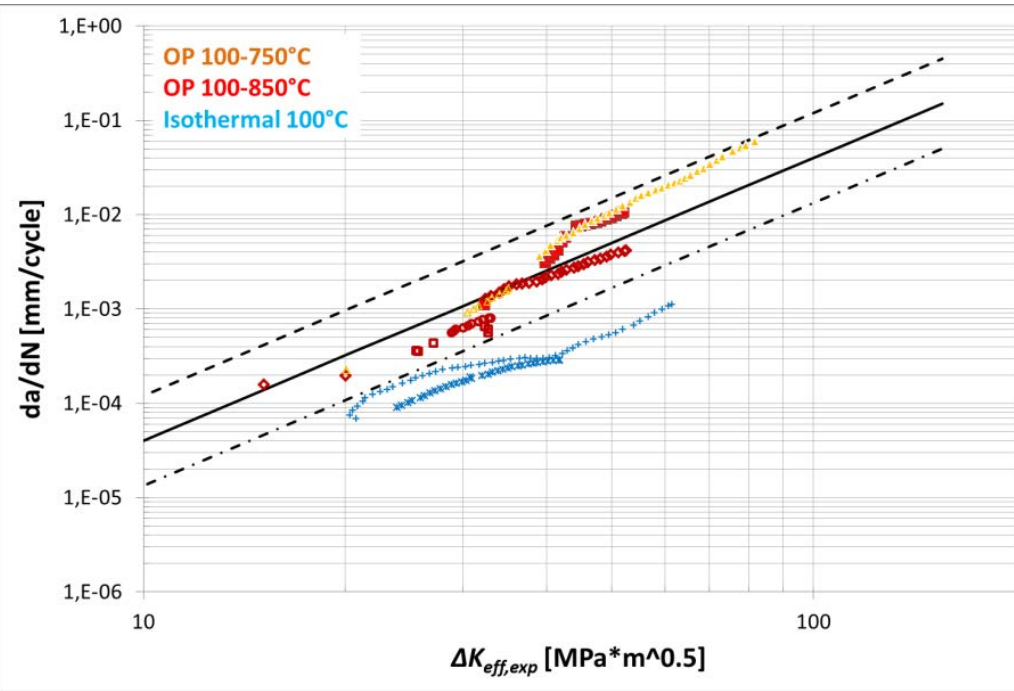

- Test $2,100-850 \mathrm{C}, \mathrm{OP}, 1 \mathrm{~h}$ hold, $\mathrm{R}=-1, \Delta \sigma=336 \mathrm{MPa}$

- Test $2,100-850 \mathrm{C}, \mathrm{OP}, 10$ s hold, $\mathrm{R}=-1, \Delta \sigma=280 \mathrm{MPa}$

- Test 3, 100-850C, OP, 10 s hold, $R=-1, \Delta \sigma=300 \mathrm{MPa}$

Test 4, 100-750C, OP, 10s hold, $R=-1, \triangle 0=350 \mathrm{MPa}$

Test $4,100-750 C, O P$, $1 \mathrm{~h}$ hold, $R=-1, \Delta \sigma=350 \mathrm{MPa}$

Test $12,100 \mathrm{C}, \mathrm{R}=-1, \Delta \mathrm{\sigma}=300 \mathrm{MPa}$

Test $13,100 \mathrm{C}, \mathrm{R}=0, \Delta \sigma=150 \mathrm{MPa}$

- Test $15,100-850 \mathrm{C}$, OP, 10 s hold, $R=0, \Delta \mathrm{o}=150 \mathrm{MPa}$

-Trendline, OP-TMF

- - OP-TMF, lower bound

- - OP-TMF, upper bound

Figure 13 - Crack growth rate during OP-TMF and isothermal fatigue testing at $100^{\circ} \mathrm{C}$. a: $d a / d N$ vs $\Delta K$, b: da/dN vs $\Delta K_{\text {eff, exp }}$ 


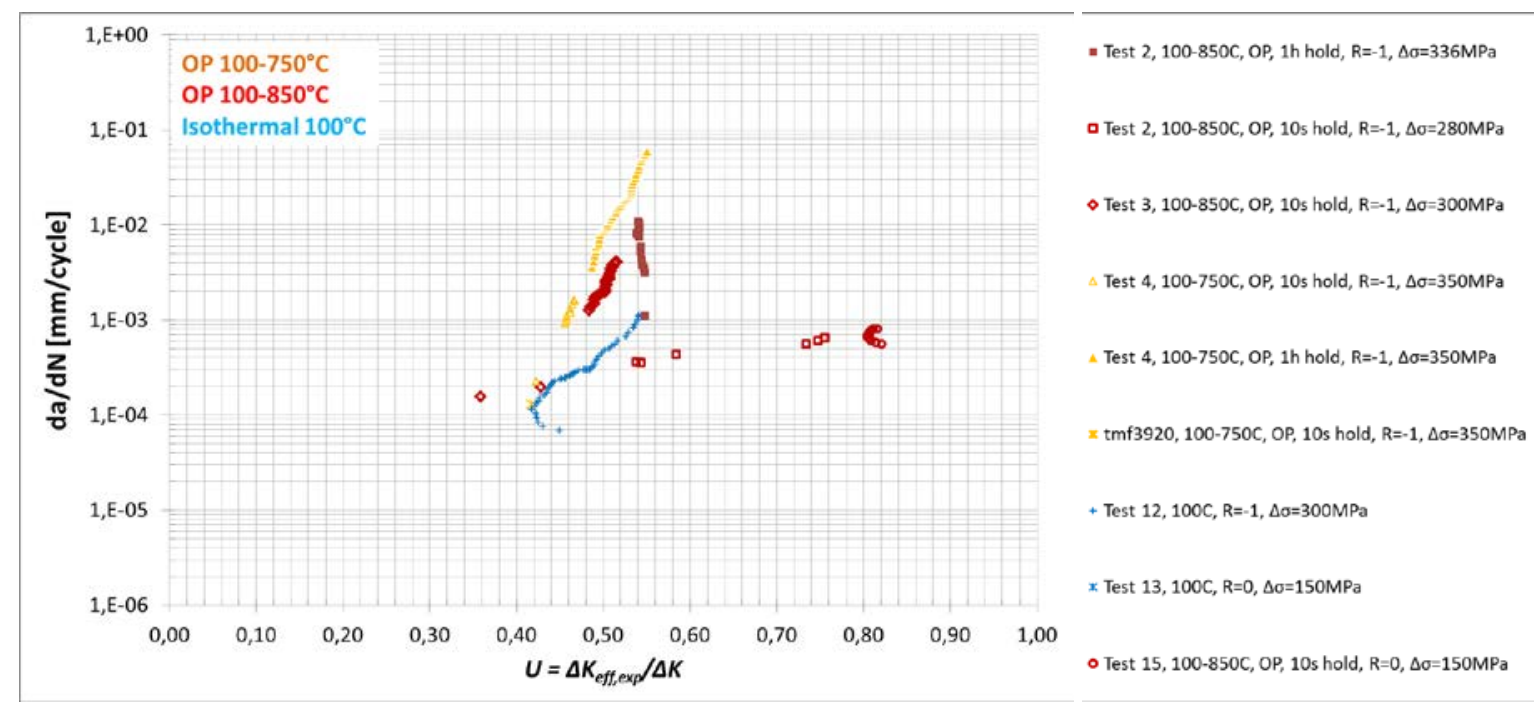

Figure 14 - Crack growth rate vs experimentally observed crack closure factor during OP-TMF and isothermal fatigue testing at $100^{\circ} \mathrm{C}$.

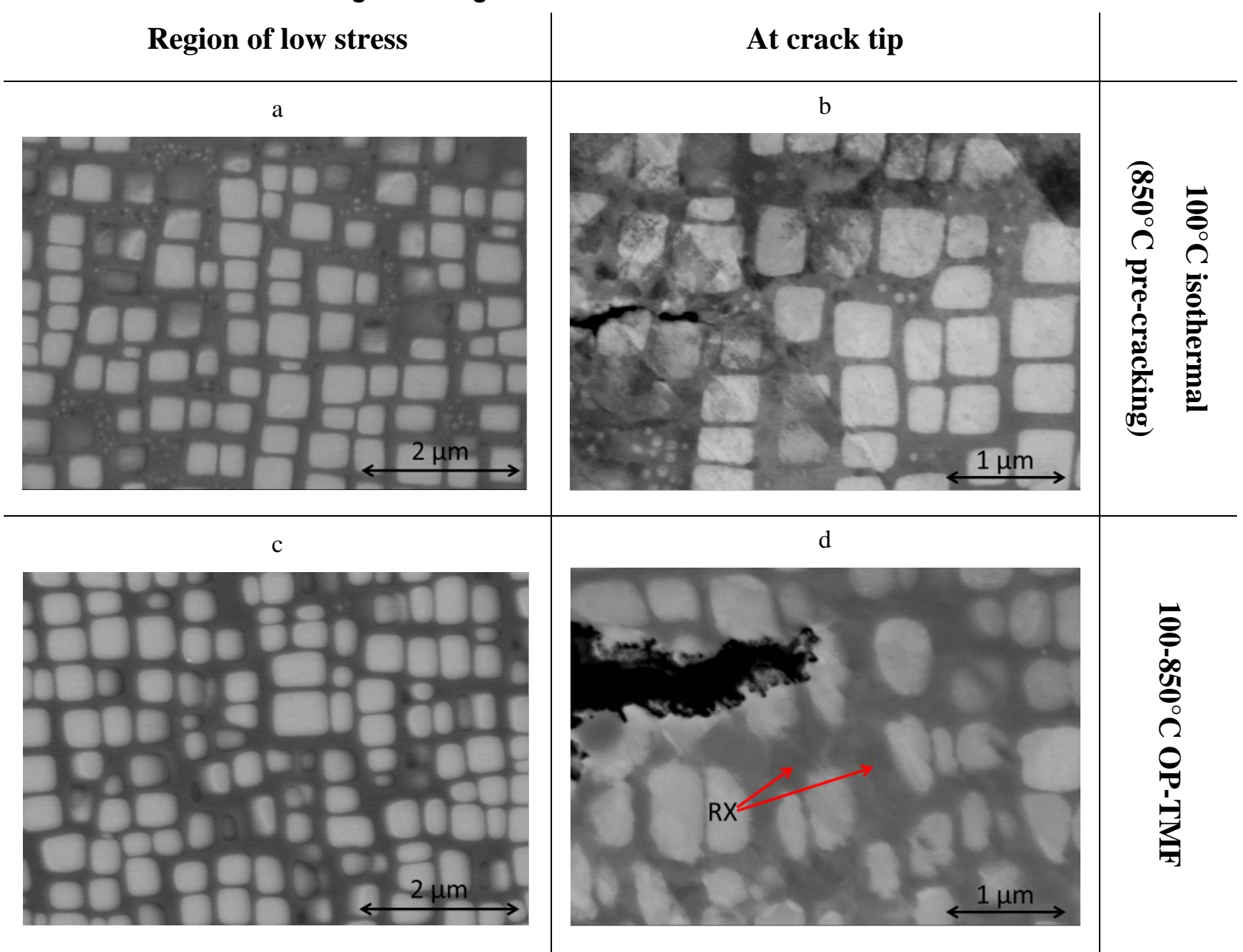

Figure 15 - Backscattered electron images showing the microstructures of test specimens subjected to different testing conditions. a: Test $13,100^{\circ} \mathrm{C}$ isothermal (pre-cracked at $850^{\circ} \mathrm{C}$ ), at region of low stress. b: Test $13,100^{\circ} \mathrm{C}$ isothermal (pre-cracked at $850^{\circ} \mathrm{C}$ ), at crack tip. c: Test 15, $100-850^{\circ} \mathrm{C}$ OP-TMF, at region of low stress. d: Test $15,100-850^{\circ} \mathrm{C}$ OP-TMF, at crack tip. Recrystallization $(R X)$ is marked by red arrows. 


\subsection{Influence of cycle type}

In order to facilitate the comparison of different cycle types, the damage temperature $\left(\mathrm{T}_{\mathrm{d}}\right)$ is defined as the temperature where $K=K_{\max }$. In the present test, there was no significant difference in crack growth rate vs $\Delta K_{\text {eff,exp }}$ between IP-TMF and isothermal tests at the same $\mathrm{T}_{\mathrm{d}}$. The crack growth rate vs $\Delta K_{\text {eff,exp }}$ for OP-TMF was however significantly higher than for isothermal tests at the same $T_{d}$. The proposed explanation for this is that the material ahead of the crack tip has been weakened by $\gamma^{\prime}$ dissolution and recrystallization in the high temperature end of the OP-TMF cycle. When microstructural degradation has a significant influence on the crack growth rate, it is to be expected that the crack growth rate depends not only on $\mathrm{T}_{\mathrm{d}}$ but also on $\mathrm{T}_{\max }$. For the present OP-TMF tests, a significant difference would be expected between $\mathrm{T}_{\max }=750^{\circ} \mathrm{C}$ and $\mathrm{T}_{\max }=850^{\circ} \mathrm{C}$ if the rate of $\gamma^{\prime}$ dissolution at the crack tip were limited by diffusion, since the diffusivity is strongly temperature dependent. Since no such difference is seen, it appears that the degradation observed at the crack tip in the OP-TMF tests is not limited by diffusion at $\mathrm{T}_{\max }=750^{\circ} \mathrm{C}$ or $\mathrm{T}_{\max }=850^{\circ} \mathrm{C}$. An explanation for this may be that high diffusion rates are achieved via pipe diffusion at dislocations, as observed previously for the polycrystalline superalloy IN792 at $750^{\circ} \mathrm{C}^{34}$. During IPTMF testing, $T_{d}=T_{\max }$ and the single parameter of $T_{d}$ is in this case sufficient to describe the temperature dependence both due to mechanical response and due to microstructural degradation. Since the thermal cycle dependence can be simplified as a dependence on $\mathrm{T}_{\mathrm{d}}$, it is reasonable that the IP-TMF cycle in a testing context can be simplified as an isothermal fatigue cycle at $\mathrm{T}=\mathrm{T}_{\mathrm{d}}$, without significant differences in crack growth rate. This observation pertains to the specific tests conducted in the present work and should not be generalized to other materials or testing conditions.

\subsection{Influence of hold time}

For the OP-TMF tests, no significant influence of hold time was observed on the crack growth rates. When the crack growth rates are plotted against $\Delta K_{\text {eff,exp }}$, the crack growth rates of tests with 1 h hold time tend to be slightly higher than in tests with 10s hold time, see Figure 12b. This difference is consistent with the proposed explanation of $\gamma^{\prime}$ dissolution and recrystallization being responsible for increased crack growth rate during OP-TMF compared with isothermal fatigue testing at $100^{\circ} \mathrm{C}$. The difference in crack growth rate due to the hold time is however not larger than the scatter of the data. For IP-TMF there is a clear hold time influence on the crack growth rate vs the full range of $\Delta K$, but no significant difference if the crack growth rate is plotted vs $\Delta K_{\text {eff,exp, }}$ see Figure 9 and Figure 10. In other words, the hold time influence can be completely attributed to a hold time effect on the crack closure behaviour. The hold time causes the crack to remain open during a larger part of the cycle and in some cases during the entire cycle. The crack closure behaviour is further discussed in the following section.

\subsection{Crack closure}

In many of the present tests, the crack driving force was influenced by crack closure. This was taken into account by experimentally evaluating the effective stress intensity factor range, see sections 2.7 and 2.8.2. Fatigue crack closure has been extensively studied and a review of the physical phenomena has been published by Pippan and Hohenwarter $^{35}$. Among the crack closure mechanisms identified by Suresh and Ritchie ${ }^{36}$, plasticity induced crack 
closure is expected to be the dominant one for the present tests. Not only plasticity, but also creep, is expected to contribute to the inelastic deformation at the crack tip and thereby to the crack closure. Creep and plasticity induced crack closure may therefore be a more appropriate term. Wedging mechanisms, related to crack surface asperities or corrosion products, are not expected to have had a significant influence in the present tests. Wedging is expected to result in an increase in minimum strain during the tests, but this was not observed. In IP-TMF tests, a hold time of 1h or more decreases the crack opening force. The opposite would be expected in the case of oxide-induced crack closure. The observed decrease of the crack opening force with hold time is assumed to be due to creep deformation and relaxation at the crack tip. Modelling work by several different authors show that a decrease in crack opening force with increasing hold time is to be expected due to creep ${ }^{37,38,39}$.

\subsection{Crystallographic crack growth}

During $100^{\circ} \mathrm{C}$ isothermal testing or OP-TMF, where the maximum stress is reached at low temperature, there is a possibility for crystallographic crack growth in the single crystal alloy studied ${ }^{27}$. In the present testing, the aim was to generate data for Mode I crack growth and care has therefore been taken to avoid crystallographic crack growth, which is known to occur along the $\{111\}$ planes $^{27}$. Crystallographic crack growth was avoided by pre-cracking the specimens isothermally at $750^{\circ} \mathrm{C}$ or $850^{\circ} \mathrm{C}$. The results and conclusions of the present work regarding OP-TMF crack growth are thus only applicable to Mode I crack growth. In order to describe the crack growth behaviour of the material in a general sense one would also need to consider the possibility of crystallographic crack growth at low temperature. Modelling and test data evaluation for crystallographic crack growth is more complex than for Mode I crack growth. A crack driving force parameter for crystallographic crack growth has recently been proposed by Busse et al. ${ }^{40,41}$.

\subsection{Influence of specimen geometry}

The two tested specimen geometries are fairly similar apart from the notch, see Figure 1 . The difference in stress gradient ahead of the notch is not expected to influence the recorded crack growth rates since the specimens were pre-cracked. The stress state of the two specimens is expected to be fairly similar in terms of constraint. Therefore, the two specimen geometries are expected to display very similar crack growth behaviour. In the present tests there was in fact no apparent influence of specimen geometry on the crack growth rate vs $\Delta K$ or vs $\Delta K_{\text {effexp. This is }}$ regarded as a verification of the testing and evaluation method, especially concerning the specimen specific functions used to describe the stress intensity factor and stiffness vs crack length. 
Fatigue crack growth testing was performed on a single crystal nickel base superalloy, both under isothermal fatigue and TMF conditions. A compliance-based method is proposed to experimentally evaluate the crack opening stress and thereby obtain the effective stress intensity factor range $\Delta K_{\text {effexp }}$ for both isothermal and TMF conditions.

- No significant difference in crack growth rate vs $\Delta K_{\text {effexp }}$ is observed between IP-TMF tests and isothermal tests at the maximum temperature.

- For IP-TMF, the crack growth rate is increased if a hold time is applied at maximum temperature. This increase in crack growth rate is due to a reduction in crack opening force, resulting in an increase in the effective stress intensity factor range which accelerates the cycle dependent crack growth.

- For the IP-TMF tests, the crack growth rate vs $\Delta K_{\text {effexp }}$ can be described by one trendline for $\mathrm{T}_{\max }=750^{\circ} \mathrm{C}$ and one for $\mathrm{T}_{\max }=850^{\circ} \mathrm{C}$. For each temperature, all tests fall within a factor 3 scatterband, regardless of dwell time or stress ratio. These manually fitted trendlines have the same exponent, $\mathrm{m}$ and a moderate factor 2 difference in the coefficient, $\mathrm{C}$.

- For OP-TMF, the crack growth rate of the present tests was insensitive to the maximum temperature and also to the length of hold time at maximum temperature. The maximum temperature of the tests was either $750^{\circ} \mathrm{C}$ or $850^{\circ} \mathrm{C}$ and hold times of 10 s and $1 \mathrm{~h}$ were used.

- For all OP-TMF tests, the crack growth rates vs $\Delta K_{\text {eff, exp }}$ collapse along one trendline, within a factor 3 scatterband. The crack growth rates vs $\Delta K_{\text {eff,exp }}$ of isothermal fatigue tests at $100^{\circ} \mathrm{C}$ fall below the scatterband for OP-TMF, even though the actual advancement of the crack presumably occurs at the same temperature as in the OP-TMF tests. Microstructural investigations, in combination with findings of other researchers, suggests that local dissolution of $\gamma^{\prime}$ and recrystallization at the crack tip is a likely explanation for the observed difference in crack growth rate between $100^{\circ} \mathrm{C}$ isothermal tests and OP-TMF tests with a minimum temperature of $100^{\circ} \mathrm{C}$. 


\section{Acknowledgements}

The work has been supported financially by Siemens Industrial Turbomachinery AB in Finspång, Sweden and the Swedish Energy Agency, via the Research Consortium of Materials Technology for Thermal Energy Processes,

Grant No. KME-702. The authors would like to thank Per Almroth at Siemens Industrial Turbomachinery AB for valuable input and discussions. 


\footnotetext{
${ }^{1}$ Arrell D, Hasselqvist M, Sommer J, Moverare J. “On TMF Damage, Degradation Effects, and the Associated Tmin Influence on TMF Test Results in $\gamma / \gamma$ ’ Alloys”, in: Superalloys 2004.
}

${ }^{2}$ Moverare, Johan \& C. Reed, Roger. (2014). Thermomechanical fatigue in single crystal superalloys. MATEC Web of Conferences. 14. 06001. 10.1051/matecconf/20141406001.

${ }^{3}$ Sato, Atsushi \& Moverare, Johan \& Hasselqvist, Magnus \& C. Reed, Roger. (2012). On the Mechanical Behavior of a New Single-Crystal Superalloy for Industrial Gas Turbine Applications. Metallurgical and Materials Transactions A. 43. 10.1007/s11661-011-0995-2.

${ }^{4}$ Hong, H \& Kang, J.G. \& Choi, Baig Gyu \& Kim, In \& S. Yoo, Y \& Y. Jo, C. (2011). A comparative study on thermomechanical and low cycle fatigue failures of a single crystal nickel-based superalloy. International Journal of Fatigue - INT J FATIGUE. 33. 1592-1599. 10.1016/j.ijfatigue.2011.07.009.

${ }^{5}$ Segersäll, M., Kontis, P., Pedrazzini, S., Bagot, P.A.J., Moody, M.P., Moverare, J.J., and Reed, R.C. (2015). Thermal-mechanical fatigue behaviour of a new single crystal superalloy: Effects of Si and Re alloying. Acta Materialia 95, 456-467.

${ }^{6}$ F. Sun, J. Zhang, H. Harada, Deformation twinning and twinning-related fracture in nickel-base single-crystal superalloys during thermomechanical fatigue cycling, Acta Mater., 67 (2014), pp. 45-57

${ }^{7}$ Segersäll M, Moverare JJ, Leidermark D, Johansson S. In- and out-of-phase Thermomechanical Fatigueof a NiBased Single-Crystal Superalloy, in: EuroSuperalloys 2014

${ }^{8}$ Han G. M., Yu J. J., Sun X. F., and Hu Z. Q., “Thermo-mechanical fatigue behavior of a single-crystal nickelbased superalloy,” Materials Science and Engineering A, vol. 528, pp. 6217-6224, 2011.

${ }^{9}$ Segersäll, Mikael \& Leidermark, Daniel \& Moverare, Johan. (2015). Influence of crystal orientation on the thermomechanical fatigue behaviour in a single-crystal superalloy. Materials Science and Engineering A. 623. 6877. 10.1016/j.msea.2014.11.026.

${ }^{10}$ Kontis P. et al., The Role of Oxidized Carbides on Thermal-Mechanical Performance of Polycrystalline Superalloys. Metallurgical and Materials Transactions A: Physical Metallurgy and Materials Science. 49, 42364245 (2018)

${ }^{11}$ Moverare, Johan \& Segersäll, Mikael \& Sato, Atsushi \& Johansson, Sten \& Roger, Reed. (2012).

Thermomechanical Fatigue of Single-Crystal Superalloys: Influence of Composition and Microstructure. Proceedings of the International Symposium on Superalloys. 10.1002/9781118516430.ch40.

12 Zhang, J.X. \& Harada, H \& Ro, Y \& Koizumi, Yuichiro \& Kobayashi, T. (2008). Thermomechanical fatigue mechanism in a modern single crystal nickel base superalloy TMS-82. Acta Materialia. 56. 2975-2987. 10.1016/j.actamat.2008.02.035.

${ }^{13}$ Sun, Fei \& Zhang, Jianxin \& Harada, Hiroshi. (2014). Deformation twinning and twinning-related fracture in nickel-base single-crystal superalloys during thermomechanical fatigue cycling. Acta Materialia. 67. 45-57. 10.1016/j.actamat.2013.12.011.

${ }^{14}$ Neuner, F.C. \& Tetzlaff, Ulrich \& Mughrabi, Hael. (2003). Enhancement of Thermomechanical Fatigue Resistance of a Monocrystalline Nickel-base Superalloy by Pre-rafting. ASTM Special Technical Publication. 112126. 
${ }^{15}$ Zhang, J.X. \& Harada, H \& Ro, Y \& Koizumi, Yuichiro. (2006). Superior thermo-mechanical fatigue property of a superalloy due to its heterogeneous microstructure. Scripta Materialia. 55. 731-734.

10.1016/j.scriptamat.2006.06.012.

16 Johansson, Sten \& Moverare, Johan \& Leidermark, Daniel \& Simonsson, Kjell \& Kanesund, Jan. (2010). Investigation of localized damage in single crystals subjected to thermalmechanical fatigue (TMF). Procedia Engineering. 2. 657-666. 10.1016/j.proeng.2010.03.071.

${ }^{17}$ Yu, Jinjiang \& Han, Guoming \& Chu, Zhaokuang \& Sun, Xiaofeng \& Jin, T \& Hu, Zhuangqi. (2014). High temperature thermo-mechanical and low cycle fatigue behaviors of DD32 single crystal superalloy. Materials Science and Engineering: A. 592. 164-172. 10.1016/j.msea.2013.10.055.

${ }^{18}$ Zhang, P., Zhu, Q., Chen, G., Wang, C., "Review on thermo-mechanical fatigue behavior of nickel-base superalloys” Materials Transactions, (2015) 56 (12), pp. 1930-1939.

${ }^{19}$ Rau, C.A. \& Gemma, A.E. \& Leverant, G.R.. (1973). Thermal-mechanical fatigue crack propagation in nickel and cobalt base superalloys under various strain-temperature cycles. ASTM STP. 520. 166-178.

${ }^{20}$ Kontis P. et al., in Superalloys 2016 (John Wiley \& Sons, Inc., 2016; http://doi.wiley.com/10.1002/9781119075646.ch82), pp. 763-772.

${ }^{21}$ Kraemer, Karl \& Mueller, Falk \& Oechsner, M. (2017). Application-oriented description of time-/temperature dependent crack growth in a conventionally cast nickel-based superalloy. International Journal of Fatigue. 96. 78-88. 10.1016/j.ijfatigue.2016.11.025.

${ }^{22}$ Moverare, J.J., and Gustafsson, D. (2011). Hold-time effect on the thermo-mechanical fatigue crack growth behaviour of Inconel 718. Materials Science and Engineering A 528, 8660-8670.

${ }^{23}$ Esmaeilzadeh, Mojtaba \& Qods, Fathallah \& Arabi, Hossein \& Mohammad Sadeghi, Bagher. (2016). An investigation on crack growth rate of Fatigue and induction heating thermo-mechanical fatigue (TMF) in Hastelloy X superalloy via LEFM, EPFM and integration models. International Journal of Fatigue. 97. 135-149. 10.1016/j.ijfatigue.2016.12.036.

${ }^{24}$ T. Radzicki, A \& S. Johnson, W \& Neu, Richard \& Annigeri, Balkrishna \& Ziegler, Brett. (2017). Impact of compressive hold on out-of-phase thermomechanical fatigue crack growth in IN 718: Impact of Compressive Hold on OP TMF Crack Growth in IN 718. Fatigue \& Fracture of Engineering Materials \& Structures. 40.

10.1111/ffe.12584.

${ }^{25}$ Moverare, Johan \& Kontis, Paraskevas \& Johansson, Sten \& C. Reed, Roger. (2014). Thermomechanical fatigue crack growth in a cast polycrystalline superalloy. MATEC Web of Conferences. 14.

10.1051/matecconf/20141419004.

${ }^{26}$ Walter W. Milligan and Stephen D. Antolovich, "Deformation Modeling and Constitutive Modeling for Anisotropic Superalloys”, NASA contractor report 4215, 1989

${ }^{27}$ Palmert, F., Moverare, J., Gustafsson, D., and Busse, C. (2018). Fatigue crack growth behaviour of an alternative single crystal nickel base superalloy. International Journal of Fatigue 109.

${ }^{28}$ R.C. Reed, J.J. Moverare, A. Sato, F. Karlsson, M. Hasselqvist, “A new single crystal superalloy for power generation applications”, Superalloys 2012: 12th International Symposium on Superalloys, TMS, 2012

${ }^{29}$ D. Ewest et al., A modified compliance method for fatigue crack propagation applied on a single edge notch specimen. International Journal of Fatigue. 92, 61-70 (2016).

${ }^{30}$ W. Elber, “Fatigue crack closure under cyclic tension”, (1970) Engineering Fracture Mechanics, 2 (1), pp. 37-44 
${ }^{31}$ S. Blandford, R \& Daniewicz, Steve \& D. Skinner, J. (2002). Determination of the opening load for a growing fatigue crack: Evaluation of experimental data reduction techniques and analytical models. Fatigue \& Fracture of Engineering Materials \& Structures. 25.17 - 26. 10.1046/j

${ }^{32}$ Standard Test Method for Measurement of Fatigue Crack Growth Rates, ASTM E647, 2014

${ }^{33}$ Moverare, Johan \& Johansson, Sten. (2010). Damage mechanisms of a high-Cr single crystal superalloy during thermomechanical fatigue. Materials Science and Engineering A. 527. 553-558. 10.1016/j.msea.2009.08.023.

${ }^{34}$ Kontis, Paraskevas \& Li, Zhuangming \& Collins, David \& Cormier, Jonathan \& Raabe, Dierk \& Gault, Baptiste. (2018). The effect of chromium and cobalt segregation at dislocations on nickel-based superalloys. Scripta Materialia. 145. 76. 10.1016/j.scriptamat.2017.10.005.

${ }^{35}$ Pippan, Reinhard \& Hohenwarter, Anton. (2017). Fatigue crack closure: a review of the physical phenomena: Fatigue Crack Closure. Fatigue \& Fracture of Engineering Materials \& Structures. 40. 10.1111/ffe.12578.

${ }^{36}$ Suresh, S., Ritchie, R.O., "Propagation of short fatigue cracks”, (1984) International Metals Reviews, 29 (1), pp. 445-473.

${ }^{37}$ Huseyin, S., Wei, S., "The significance of crack closure under high temperature fatigue crack growth with hold periods”, (1989), Engineering Fracture Mechanics, 33 (3), pp. 371-388.

${ }^{38}$ Ramirez, J., Potirniche, G.P., Pugesek, H., Shaber, N., Taylor, M., Stephens, R., Charit, I. “Predicting creepfatigue crack growth rates in Alloy 709 using finite element simulations of plasticity and creep-induced crack closure" (2018) MATEC Web of Conferences, 165, art. no. 13005

${ }^{39}$ Potirniche, G.P., "Modeling of creep-fatigue interaction effects on crack growth at elevated temperatures”, (2018) MATEC Web of Conferences, 165, art. no. 05004

${ }^{40}$ Busse, C., Palmert, F., Sjödin, B., Almroth, P., Gustafsson, D., Simonsson, K., Leidermark, D., "Prediction of crystallographic cracking planes in single-crystal nickel-base superalloys”, (2018) Engineering Fracture Mechanics, 196, pp. 206-223.

${ }^{41}$ Busse, C., Palmert, F., Wawrzynek, P., Sjödin, B., Gustafsson, D., Leidermark, D., “Crystallographic crack propagation rate in single-crystal nickelbase superalloys”, (2018) MATEC Web of Conferences, 165, art. no. 13012. 